NASA Technical Memorandum 105863

\title{
Integrity Testing of Brush Seal in Shroud Ring of T-700 Engine
}

Robert C. Hendricks, Thomas A. Griffin, George B. Bobula, and Robert C. Bill

Lewis Research Center

Cleveland, Ohio

and

Harold W. Howe

Technetics Corporation

Deland, Florida

Prepared for the

Seals Workshop

sponsored by the NASA Lewis Research Center

Cleveland, Ohio, August 5-6, 1992 


\title{
INTEGRITY TESTING OF BRUSH SEAL IN SHROUD RING OF T-700 ENGINE
}

\author{
Robert C. Hendricks, Thomas A. Griffin, George A. Bobula, and Robert C. Bill \\ National Aeronautics and Space Administration \\ Lewis Research Center \\ Cleveland, Ohio, 44135 \\ Harold W. Howe \\ Technetics Corporation \\ Deland, Florida
}

\section{SUMMARY}

A split-ring brush seal was fabricated, installed between two labyrinth-honeycomb shroud seals, and tested in the fourth-stage turbine of a T-700 engine. The annealed Haynes 25 bristles rubbed directly against the nonconditioned, irregular René 80 turbine blade shroud surface. A total of $21 \mathrm{hr}$ of cyclic and steady-state data were taken with surface speeds to $335 \mathrm{~m} / \mathrm{s}(1100 \mathrm{ft} / \mathrm{s})$ and shroud temperatures to $620^{\circ} \mathrm{C}$ $\left(1150^{\circ} \mathrm{F}\right)$. Wear appeared to be rapid initially, with an orange flash of hot brush fragments during the first engine startup, to minimal after $10 \mathrm{hr}$ of operation. The brush survived the testing but experienced some bristle pullouts and severe bristle wear; some turbine interface wear and possible material transfer was noted. Future design concerns center on tribological behavior at the interface with or without lubricants.

\section{INTRODUCTION}

Engine testing of brush seals has been reported (e.g., Rolls Royce (ref. 1) and Allison (ref. 2)) that demonstrated performance increases relative to labyrinth seals. These brush seal systems had smooth rotor interfaces $(<25 \mathrm{rms})$ and operated at moderate temperatures and surface speeds. Even though these tests were successful, concern over catastrophic failure of the brush, such as a loss of bristles when subjected to high surface speeds at elevated temperatures, has not been resolved.

The objectives of this program were first to demonstrate that a well-designed and manufactured brush seal could survive the "pounding" of an irregular rotor surface without catastrophic failure, second to illustrate the concept of running a combined brush and labyrinth seal system, and third to acquire metallographic data on bristles subjected to such an environment.

\section{EXPERIMENTAL BRUSH CONFIGURATION AND INSTALLATION}

A cross-sectional view of the split-ring brush seal configuration is illustrated in figure 1. A major problem in designing retrofit seals is consistency of hardware measurements, and for this experimental engine the seal was crafted to fit.

In order to fit into the existing T-700 engine fourth-stage turbine shroud, the design was required to fit into a radial clearance about half that normally used for brush seals. The $0.071-\mathrm{mm}(0.0028-\mathrm{in}$.) diameter, Haynes 25 bristles were angled $43^{\circ}$ to $50^{\circ}$ to the interface with about 2500 per inch of circumference (98.4 per millimeter of circumference). The backing washer (or fence) was angled $19^{\circ}$ to match the slope of the turbine shroud. The design clearance was $-0.51 \mathrm{~mm}(-0.02 \mathrm{in}$.) but could range to $-1.27 \mathrm{~mm}(-0.05 \mathrm{in}$.) diametral (the uncertainty reflecting that of the engine geometry) with an outside diameter of $333.9 \mathrm{~mm}$ (13.146 in.) and an inside diameter of $322.3 \mathrm{~mm}$ (12.690 in.). 
Figure 2 shows several views of the split-ring brush seal, illustrating the joint and the restraining pin hole. Figure 3 shows the unusual brush cross section that was crafted to fit the turbine shroud between the two labyrinth-honeycomb seals. Figure 4 shows a closeup view of the installed brush; and figure 5 , an overall view of the installed brush. Figure 6(a) shows the pressure tap locations in one of the shrouds. A thermocouple was installed in each shroud (fig. 6(b)); three of the four were functional. Figures 6(c) and (d) show views of the shroud ring and instrumentation lines.

Assembly of the turbine with the shroud required forcing the brush past the upstream labyrinth tooth without any visual or instrumented guidelines; see figure 7 (power turbine). Forcing the brush over the labyrinth tooth spread the bristles axially into the upstream direction. This type of spreading alters the bristle packing configuration, but the extent of alteration and the degree of spreading are unknown. Post-test results indicated that perhaps two to three upstream bristle rows remained spread with possibly one downstream bristle row in disarray. Still the brush was resilient because the remaining rows appeared to be in position. The flexibility of a brush seal and the abuse it can withstand appear to be significant.

With the brush installed, the turbine shaft was difficult to rotate, requiring $14.7 \mathrm{~N}-\mathrm{m}$ ( $130 \mathrm{in} .-1 \mathrm{lbf})$ of torque. This was a major concern because heat generation could be sufficient to melt the materials at the interface. The geared tooth rotor results (ref. 3), including material smearing, cutting, and local hot spots, indicate that high heat loads and temperatures could be present but would be confined to the interface, with the lowest heat-sinking element (the bristles) absorbing the energy. Therefore, the bristles would fail, but the effects on the power turbine should be benign.

\section{ENGINE OPERATIONS}

The T-700 turbine section was assembled and the brush seal test was "piggybacked" on the break-in of the engine. Operations consisted of the standard break-in procedures with data taken under both steady and cyclic conditions. The engine was operated a total of $21 \mathrm{hr}$, including break-in, steady state, and $10 \mathrm{hr}$ of cycling between ground and flight idle (4-min ground idle and 5 -min flight idle). Turbine speeds were 10000 and $20000 \mathrm{rpm}$, and average fourth-stage turbine shroud temperatures were 455 and $566^{\circ} \mathrm{C}$ $\left(850\right.$ and $\left.1050^{\circ} \mathrm{F}\right)$, respectively. Maximum shroud temperatures were limited to $621^{\circ} \mathrm{C}\left(1150^{\circ} \mathrm{F}\right)$. The turbine inlet temperatures were about $139 \mathrm{deg} C(250 \mathrm{deg} F)$ higher. The pressure drop measurements across the brush were up to $0.007 \mathrm{MPa}(1 \mathrm{psia})$ and varied from shroud to shroud. An assessment of the effect of the brush seal on engine performance was inconclusive and remains to be investigated further. Neither radial nor axial positions of the rotor were monitored, but such position sensors should be an integral part of the engine dynamics.

Because of concern over the $14.7 \mathrm{~N}$-m (130-in.-lbf) installed torque that was required to rotate the power turbine shaft, after about $10 \mathrm{hr}$ of engine operations the compressor and the power turbine were decoupled. The turbine shaft turned freely but not in reverse. The turbine assembly has 50 shrouded blades with irregularities (radial, to $0.229 \mathrm{~mm}(0.009 \mathrm{in}$.); circumferential, to $0.076 \mathrm{~mm}(0.003 \mathrm{in}$.); and axial, to $0.051 \mathrm{~mm}(0.002 \mathrm{in}$.)) representing protrusions into the brush and the spaces between the blade pairs. It is not known how many cycles were required to "free the bristles," but at $10000 \mathrm{rpm}$ and with 24 irregular asperities impacting each bristle (4000 impacts/s at a surface speed of $168 \mathrm{~m} / \mathrm{s}(550 \mathrm{ft} / \mathrm{s})$ ) it is assumed that brush break-in was rapid. The annealed Haynes 25 bristles rubbed against hardened René 80 blades and probably wore rapidly during the initial stages of engine break-in.

Furthermore, and of significance to engine designers, a flash was noted upon initial engine ignition that was concluded to be expulsion of brush fragments. This is important because critical components 
must be protected against initially high levels of debris generation. Analysis of these and other fragments showed severe oxidation with some degree of stiffness remaining. These fragments are not passive debris; they can cause damage to critical components. The only debris noted in the gear-tooth rotor study (ref. 3) was a "lubricant powder." Thus, surface speed, rotor roughness, and brush construction play a major role in determining the spectrum of debris generation.

\section{RESULTS AND DISCUSSION}

In any potentially destructive situation one attempts to preserve the critical components. Brush bristle wear would degrade performance, but failure of the turbine or a shaft (depending on seal location) could result in engine loss, perhaps catastrophic. So the brush seal becomes the sacrificial component, not only in this case but when running against a coated shaft. The brush seal would then be replaced at discrete intervals, such as during overhauls.

For these tests the brush rubbed the turbine blade shroud asperities smooth and did provide a distinct wear track, perhaps through transfer of material. However, no direct damage was ascribed to the turbine blade shrouds. The engine was immediately returned to service.

Before proceeding to discuss post-test results, we return to the installation of the brush into the power turbine shroud. Figures 4,5 , and 7 show views of the installed brush seal. The brush was designed for an interference of $0.51 \mathrm{~mm}(0.020 \mathrm{in}$.) diametral. The actual interference could not be determined, but estimates of the pretest brush clearance were -0.51 to $-1.27 \mathrm{~mm}(-0.02$ to $-0.05 \mathrm{in}$.) diametral. Measurements of the shrouds differed as did those for the rotor. Although the differences were only a few thousands of an inch (mils), they represented a significant percentage of the clearance gap. It was also determined that individual blade sets could have a step change of $0.229 \mathrm{~mm}(0.009 \mathrm{in}$.) from one blade set to the next. These surface irregularities are shown in the post-test photograph (fig. 8).

Upon initial engine startup, an orange burst was noted and was assumed to be expelled brush bristles (i.e., those that were inadequately attached, were pulled out by rotor irregularities, or were embedded within the blade row gaps during the blind installation and "snapped" or "yanked" or "bent" aside during engine break-in). Residual bristles from the exhaust were photographed (fig. 9). Although they appeared to be highly oxidized and stressed, they were curly and still wirey. The number of residual bristles decreased with operation until none were noted. It is assumed that at this time the bristles and the rotor were in nearly line-to-line contact (i.e., rubbed in). Precooling the bristles during the initial rub-in may mitigate bristle loss and the orange burst.

Turbine speeds to $20000 \mathrm{rpm}$ and shroud temperatures to $620^{\circ} \mathrm{C}\left(1150^{\circ} \mathrm{F}\right)$ were commonplace. These conditions provided an interface speed of $335 \mathrm{~m} / \mathrm{s}(1100 \mathrm{ft} / \mathrm{s})$ or a temperature-velocity (TV) product of over $(1100)^{2}$ with the global target of about $(1500)^{2}$ (in U.S. customary units, feet per second per degree $F$ ).

Further assessment of figure 8 shows that the leading edges of the blade sets were polished. Some brush wear was noted and expected because René 80 is hard relative to the annealed Haynes 25 and the heat-sinking capacity of the brush is very small relative to that of the rotating blade sets. The surface irregularities at the rubbing interface can be seen. Although there was some evidence of material transfer, no metallurgical samplings or rotor measurements were taken because of the tight program schedules for the engine operations. This was a major error; however, if there comes a time when the rotor can be 
looked at, some of the transferred materials may be found still embedded in the rotor even after it has undergone other program tests for General Electric Co.

Figure 10 illustrates bristle spreading after testing, with a central core of bristles rubbed (probably clip cut and worn to shape). Although the environment was hostile, the brush did not disintegrate, but bristle pullout could be noted in a few places. Some upstream bristles (two or three rows) show spreading and perhaps one row downstream (toward the exhaust). The remainder of the bristles show wear (or cutting plus wear). Detailed estimates of the bristle stubble heights are given in figure 11(a) as taken from the set of photographs in figure $11(\mathrm{~b})$ corresponding to positions (joint, $\mathrm{J}+1, \mathrm{~J}+1.5, \mathrm{~J}+2, \mathrm{~J}+2.5$, $\mathrm{J}+3, \mathrm{~J}+3.5, \mathrm{~J}+4$, and $\mathrm{J}+4.5$ ) shown in figure $11(\mathrm{a})$. The last two photographs in figure $11(\mathrm{~b})$ correspond to the minimum stubble height, where the rotor actually rubbed the fence (position $J+3$ ); the view is looking toward the bristle stubbles to show the rubbed fence. Figure $11(c)$ shows wear track and fence rub, and figure $11(d)$ shows the joint wear track.

The following measured diametral parameters in millimeters (inches) were used to establish seal clearances:

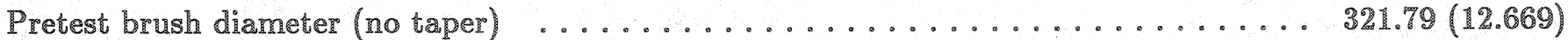

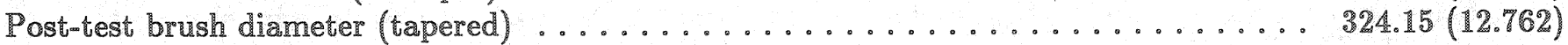

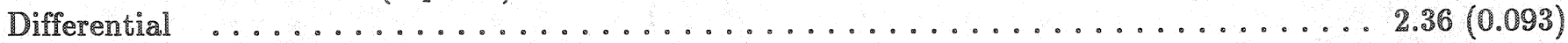

Pretest rub interface diameter $\ldots \ldots \ldots \ldots \ldots \ldots \ldots \ldots \ldots \ldots \ldots$. $\ldots \ldots \ldots$ to 322.81 (12.689 to 12.709)

Brush pretest interference $\ldots \ldots \ldots \ldots \ldots \ldots \ldots \ldots \ldots . \ldots \ldots . \ldots \ldots \ldots$ to 1.27 (0.02 to 0.04$)$

Labyrinth cold clearance ....................... 2.29 to 2.46 (0.09 to 0.097$)$

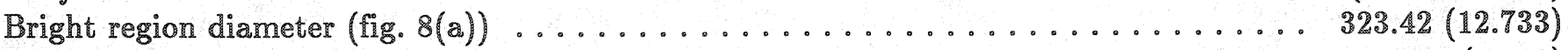

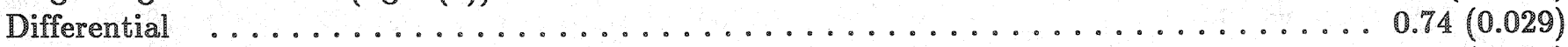

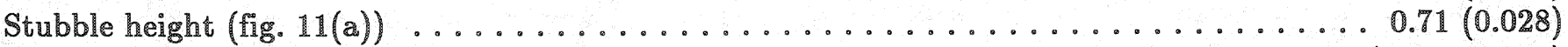

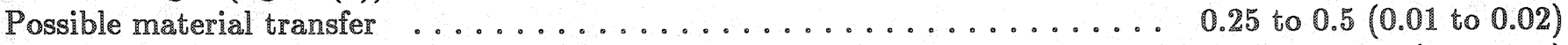

Possible engine eccentricity $\ldots \ldots \ldots \ldots \ldots \ldots \ldots \ldots \ldots \ldots \ldots \ldots \ldots \ldots \ldots \ldots$ to $0.8(0$ to 0.03$)$

Blade shroud height variation $\ldots \ldots \ldots \ldots \ldots \ldots \ldots \ldots \ldots$ to $0.23(0 \ldots$ to 0.009$)$

The average diametral clearance estimates in millimeters (inches) are as follows:

Pretest brush clearance $\ldots \ldots \ldots \ldots \ldots \ldots \ldots \ldots \ldots \ldots . . .51$ to $-1.3(-0.02$ to -0.04$)$

Post-test brush clearance ......................... 0 to $0.8(0$ to 0.03$)$

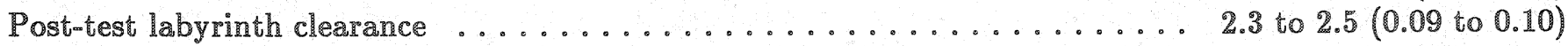

The engine parameters are as follows:

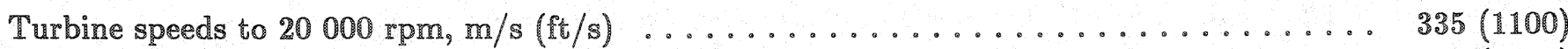

Maximum turbine shroud temperatures, ${ }^{\circ} \mathrm{C}\left({ }^{\circ} \mathrm{F}\right) \ldots \ldots \ldots \ldots \ldots \ldots \ldots$. . . . . . . . . 620 (1150)

Temperature-velocity product (approximate; in U.S. customary units $\mathrm{ft} / \mathrm{s}^{\circ}{ }^{\circ} \mathrm{F}$;

future target, $\left.\left.(1500)^{2}\right) \quad \ldots \ldots \ldots \ldots \ldots \ldots \ldots \ldots \ldots \ldots \ldots \ldots \ldots \ldots \ldots \ldots\right)^{2}$

Details of the bristles (fig. 12) show an ingrained wear pattern that is characteristic of a high spot in the rotor which cuts a shallow groove as it wears in. Furthermore, the rotor ran eccentric with respect to the seal either during cycling or steady state or both. Plots of bristle measurements show rubbing of the seal ring at $180^{\circ}$ to the pinned point and a step across the joint where the end of the split seal rubbed the rotor. 
The blind installation and operation made it difficult to assess intermediate states of wear or the health of the brush or the turbine shroud/brush interface. Although accelerometer measurements were in bounds, no detailed information concerning the orbital dynamics was available.

Metallographic results (fig. 13) illustrate some material migration along the bristle and material transfer both from and to the surface. Material smears seem to be in line with a softer material rubbing a harder material even to the point of melting. Thus, one would conclude that the interface became very hot, but the interface followed the classic Block slider problem, where the penetration depth (radial) is very small. Thus, the thermal effect at the interface appeared to be topical, wearing the brush bristles until line contact with the rotor and smear transfer of both materials occurred. Such evidence is presented in figure 14, for an individual bristle that was clipped from the brush. The clipped end was removed from the interface, and the worn end is representative of interface materials. There are material smears, oxidized spots, and apparent pits. It is not clear how the irregularities of the interface affected these results, but it is clear that materials were transferred.

Metallographic analysis of the sectioned brush will be completed and reported later.

Derby and England (ref. 4) reported excellent brush bristle and coating wear for Alloy $\mathbb{A}$ (Ni-Cr-Albase superalloy solid-solution strengthened) bristles and Triboglide coating. Alloy $\mathbb{A}$ is being used in gas turbine hot spots and develops a tenacious $\mathrm{Cr}_{2} \mathrm{O}_{3}$ and $\mathrm{Al}_{2} \mathrm{O}_{3}$, yittria-modified oxide layer. Triboglide is a chromium carbide $(\mathrm{CrC})$ containing additives of $12 \mathrm{wt} \%$ barium and calcium fluoride solid lubricants. Triboglide is based on the work of Harold Sliney at NASA Lewis but has no silver additive. The tests were performed with $1200^{\circ} \mathrm{F}$ air.

Atkinson and Bristol (ref. 5) report better wear for a cobalt alloy rubbing against chromium carbide at room temperature, but their high-temperature $\left(480^{\circ} \mathrm{C}\right)$ result shows nearly equivalent wear for either the cobalt- or the nickel-base alloy. However, the Co-alloy/CrC combination had less leakage under dynamic conditions and better wear at room temperature. The tests were conducted to simulate a CT7-9 compressor discharge seal. The brush was $129 \mathrm{~mm}$ in diameter and of standard Cross Mfg. construction.

It is apparent that the composition of both the coating and the bristles needs to be characterized with respect to the working fluid, the operating conditions, and the component life requirements. The importance of surface conditions must be emphasized. Wear decreases after operation because the brush rubs a smoother surface and bristle wear decreases line loading.

Obviously, tribological pairing is important and references 4 and 5 present a good initial look into these problems. Limitations on speed, temperature, and preloading have to be established. Furthermore, limitations on surface asperities have to be established for expedient or commercial engines even though it has been demonstrated that direct bristle rubbing of a smooth shaft could be acceptable for expedient engines (ref. 6).

\section{SUMMARY OF RESULTS AND CONCLUSIONS}

A split-ring brush seal installed between two labyrinth-honeycomb shroud seals was tested in the fourth-stage turbine of a T-700 engine. The following results were obtained and conclusions drawn: 
1. Properly designed brush seals have sufficient integrity to withstand highly irregular surface operations at surface speeds to $335 \mathrm{~m} / \mathrm{s}(1100 \mathrm{ft} / \mathrm{s})$ and shroud temperatures to $620^{\circ} \mathrm{C}\left(1150^{\circ} \mathrm{F}\right)$ with a noncentered turbine orbit during steady and cyclic loading.

2. Upon initial engine startup, bristle debris can be expected mostly in the form of fines and some larger elements. The nature and amount of debris should depend on the construction, the surface characteristics (e.g., asperities), the temperature and velocity of the interface, and the bristle preload. Critical components must be protected.

3. The post-test clearance was estimated to be line to line to $0.8 \mathrm{~mm}(0.03 \mathrm{in}$.), indicating a wellworn but still functional seal configuration. Accurate determinations of the rotor and stator dimensions along with dynamic displacement measurements are necessary for assessing bristle wear characteristics and seal clearances. A plot of bristle stubble height versus circumferential position revealed some characteristics of the rotor and engine operations.

4. Wear is expected to be initially rapid, then steady, and subsequently decreasing with time of engine operation. Cyclic operations cause more rapid wear of the bristle/rotor interface. Material transfer, smearing, and pitting of the interface are commonplace.

5. Installation torques can be high, but rub-in torques are low. Rotor reversals are not permitted.

6. Tribological pairing is important, and limitations on speed, temperature, preload, and asperities have yet to be established even though direct rubbing of a smooth shaft of an expedient engine appears plausible.

7. Although high installation torques $(14.7 \mathrm{~N}-\mathrm{m} ; 130 \mathrm{in} .-\mathrm{lbf})$ probably contributed to high bristle wear, the effects on the power turbine were benign even though heat generation and shear were sufficient to transfer materials at the interface. The René 80 is hard and has large heat capacity, and the Haynes 25 bristles are annealed and have small heat capacity. Therefore, the brush bristles failed first.

8. The pressure drop measurements across the brush seal were up to $0.007 \mathrm{MPa}$ ( 1 psia), but the effect of the brush seal on engine performance was inconclusive and requires further assessment. Radial and axial rotor sensor position monitoring is recommended.

9. Metallographic studies of the brush and rotor are being completed.

\section{REFERENCES}

1. Ferguson, J.G.: Brushes as High Performance Gas Turbine Seals. ASME Paper 88-GT-182, 1988.

2. Holle, G.; and Krishnan, M.: Gas Turbine Engine Brush Seal Applications. AIAA Paper 90-2192, 1990.

3. Hendricks, R.C.; Carlile, J.A.; and Liang, A.D.: Brush Seal Bristle Flexure and Hard Rub Characteristics. Presented at the NASA Lewis Research Center Seals Workshop, Cleveland OH, Aug. 5-6, 1992.

4. Derby, J.; and England, R.: Tribopair Evaluations of Brush Seal Applications. AlAA Paper 92-3715, 1992. 
5. Atkinson, E.; and Bristol, B.: Effects of Material Choices on Brush Seal Performance, Lubr. Eng., vol. 48, no. 9, Sept. 1992, pp. 740-746.

6. Chupp, R.; and Nelson, P.: Evaluation of Brush Seals for Limited Life Gas Turbine Engines. AIAA Paper 90-2140, 1990.

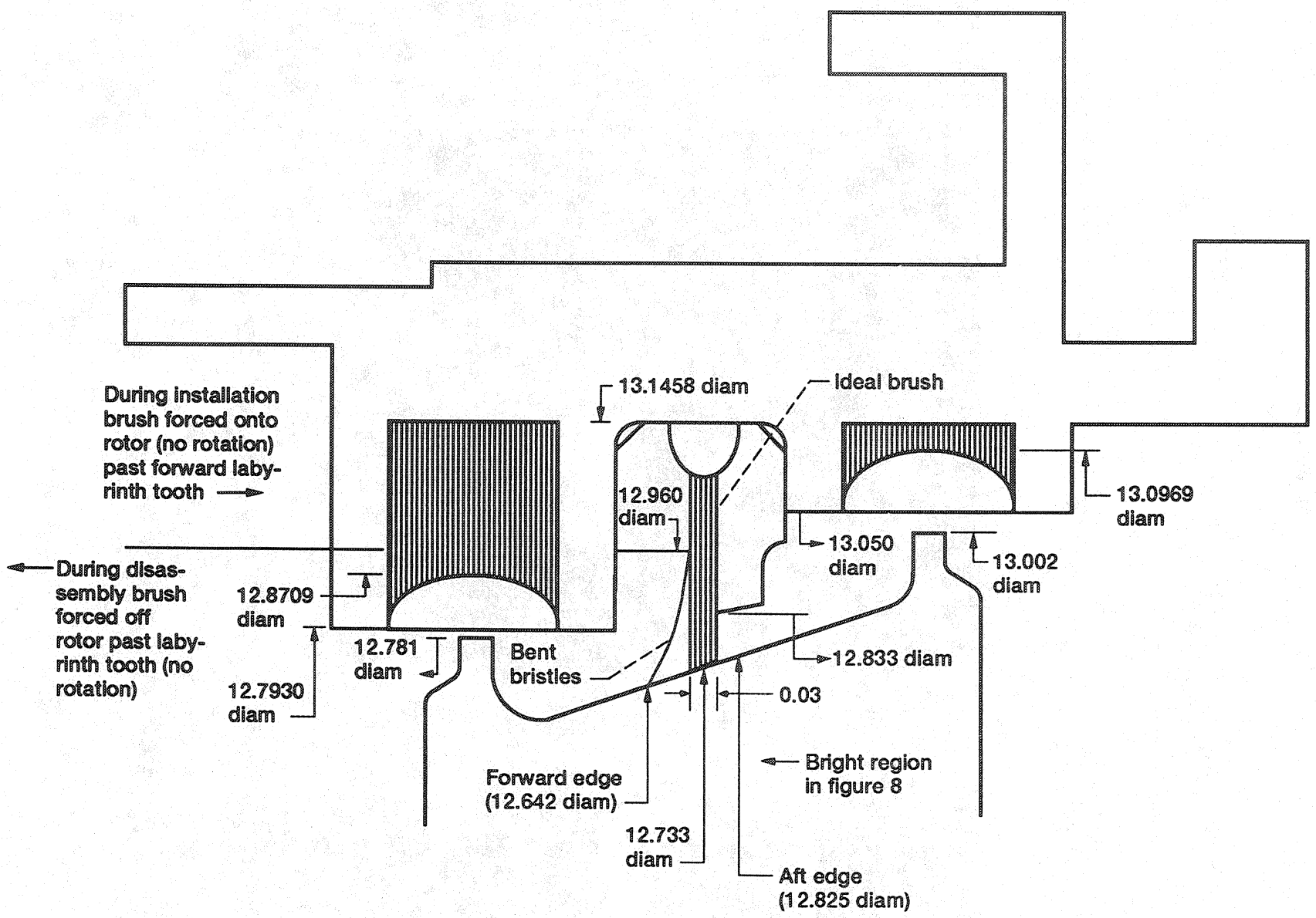

Figure 1. Cross-sectional view of split-ring brush seal configuration. (Brush design with $\sim 0.020$ in. interference. Dimensions are in inches.) 


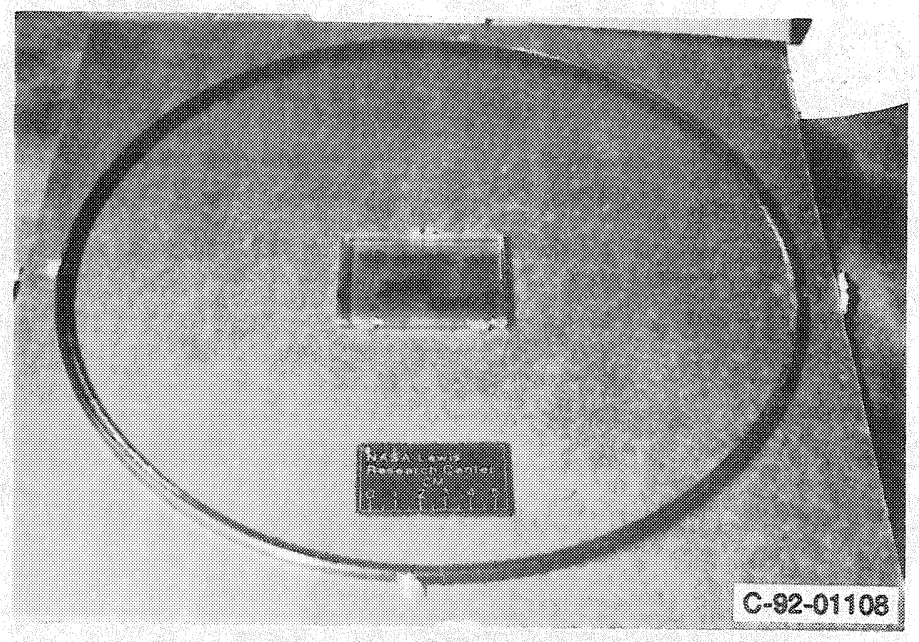

(a) Overview of brush seal.

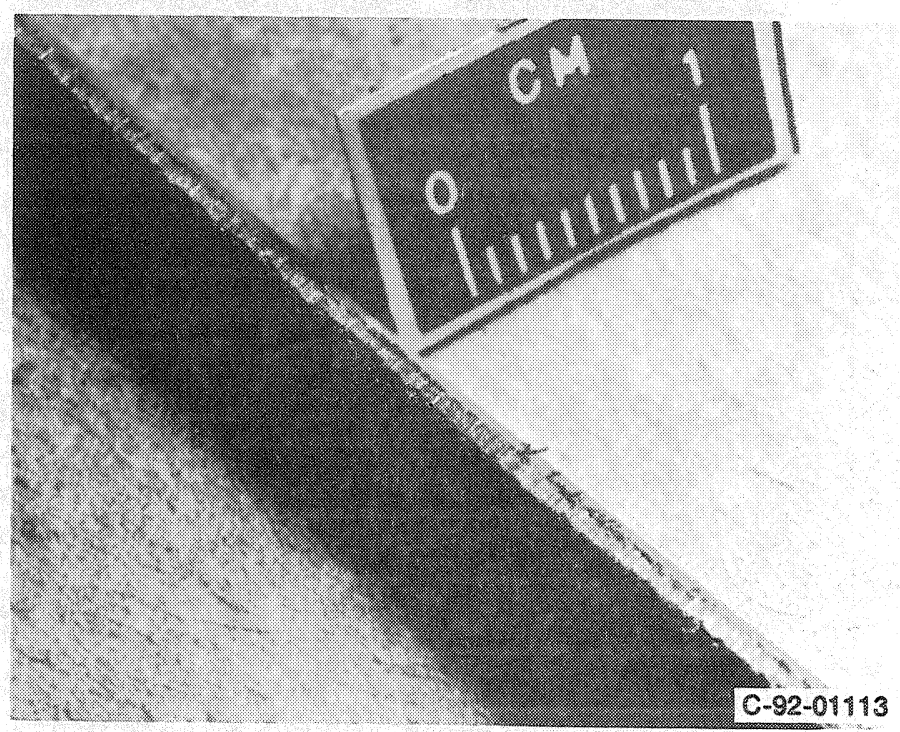

(b) Edge view of brush seal.

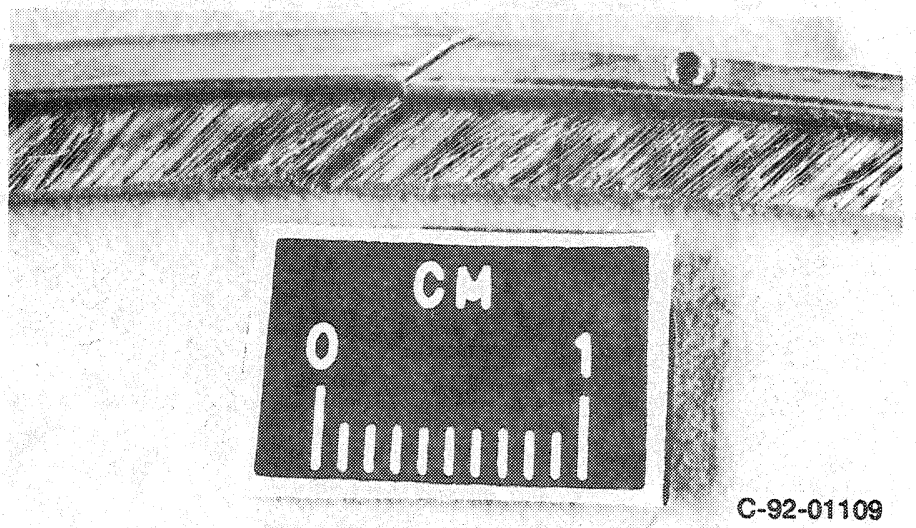

(c) Split end view.

Figure 2.-Split-ring brush seal. 


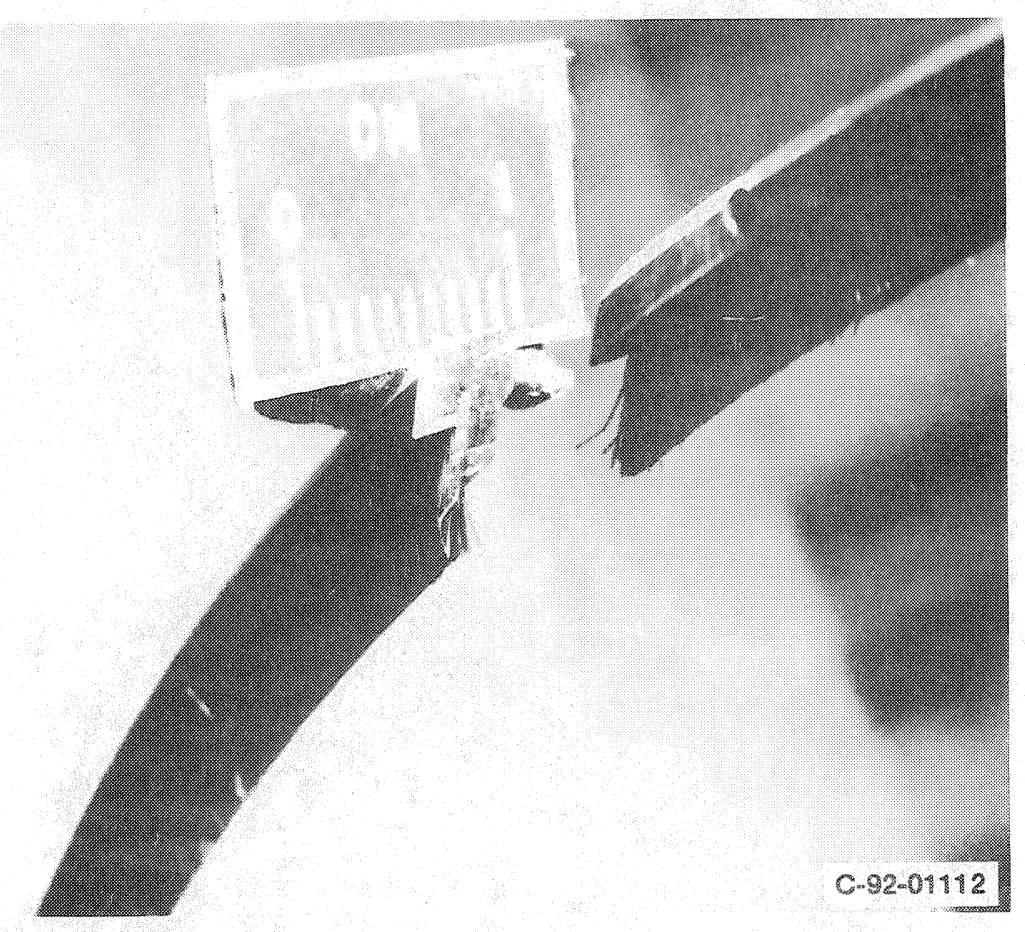

Figure 3.-Brush seal cross section crafted to fit turbine shroud between two labyrinth honeycomb seals.

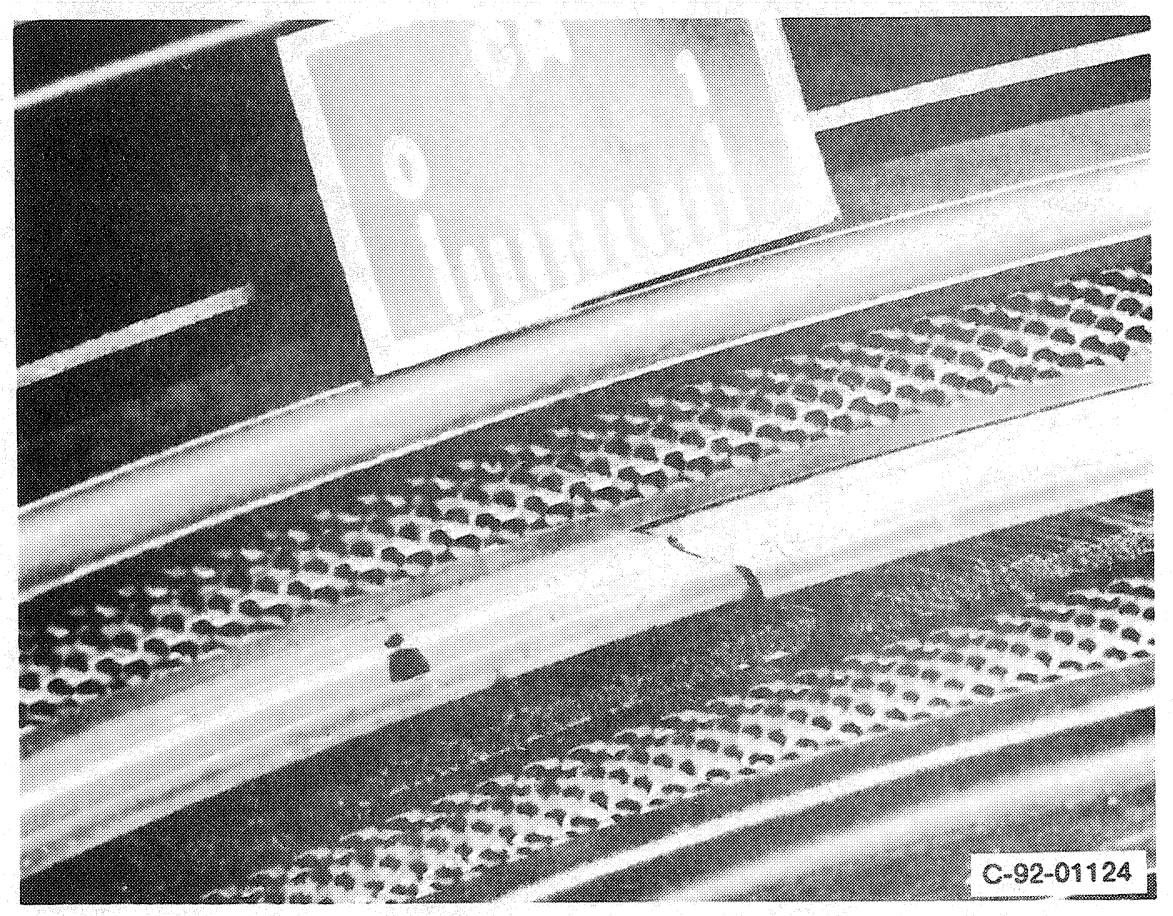

Figure 4.- View of installed brush seal. 


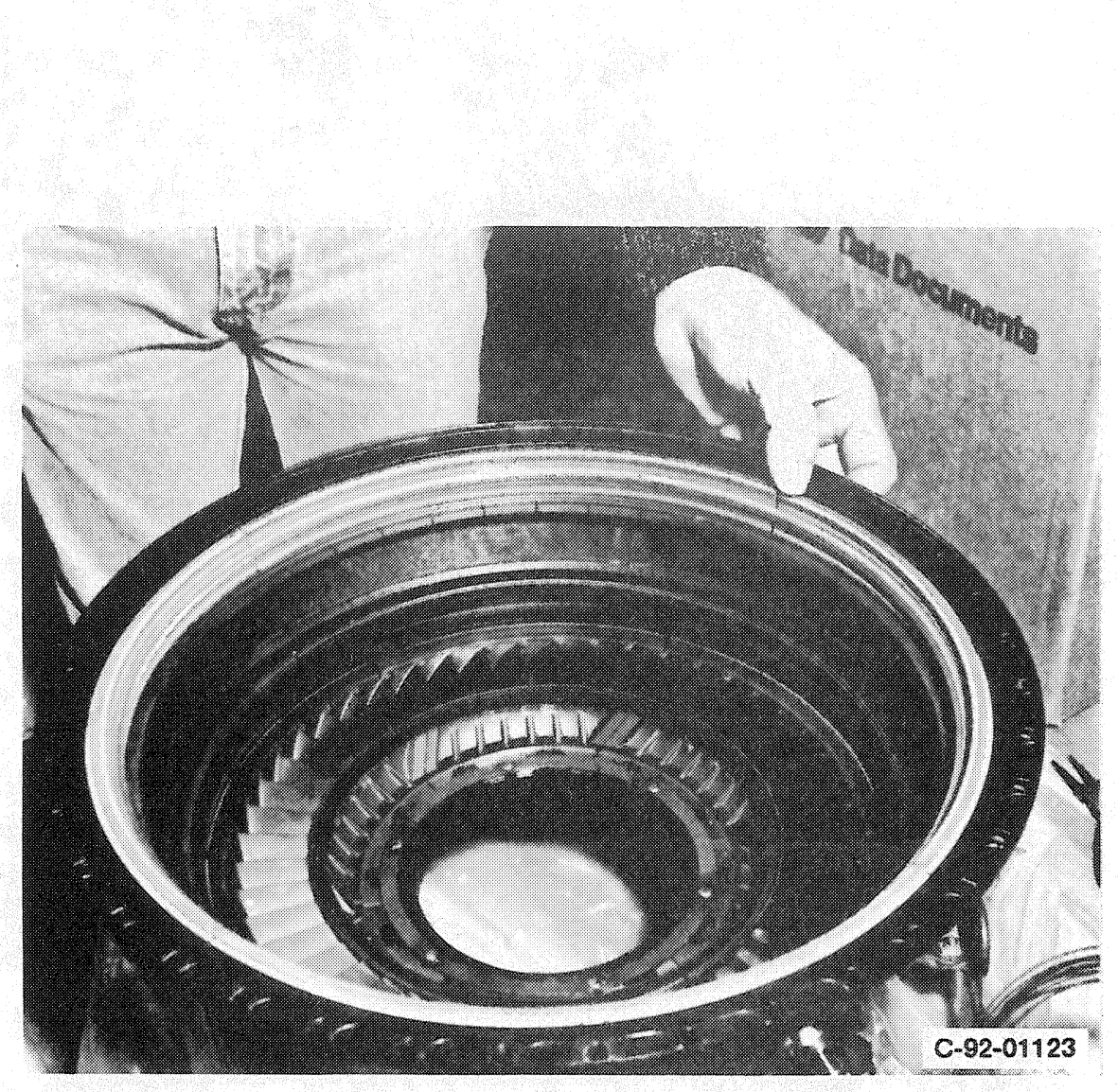

Figure 5.-Overview of installed brush seal and power turbine housing. 


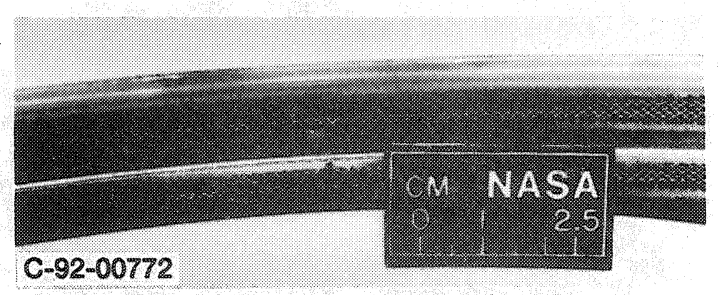

(a) Pressure tap hole.

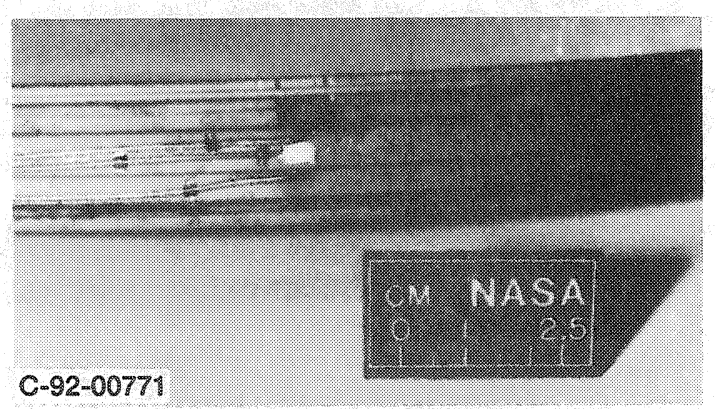

(b) Thermocouple mount and pressure tap lines.

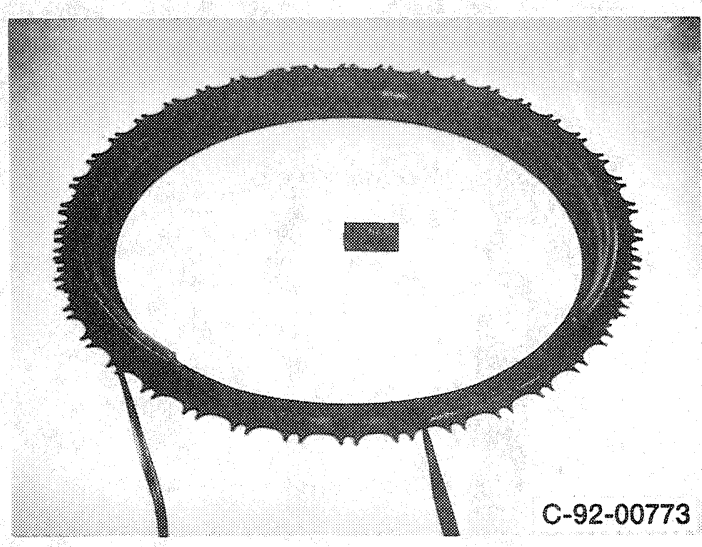

(c) Shroud ring with three seal segments and instrumentation lines - downstream view.

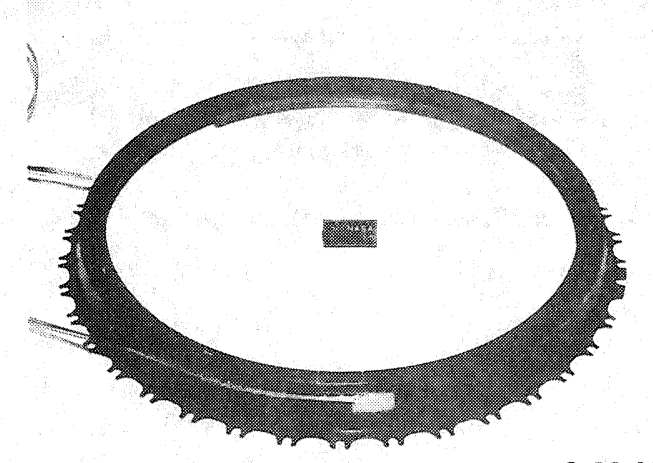

C-92-00774

(d) Shroud ring with three seal segments and instrumentation lines - upstream view.

Figure 6.-Pressure tap and thermocouple locations on shroud seal. 


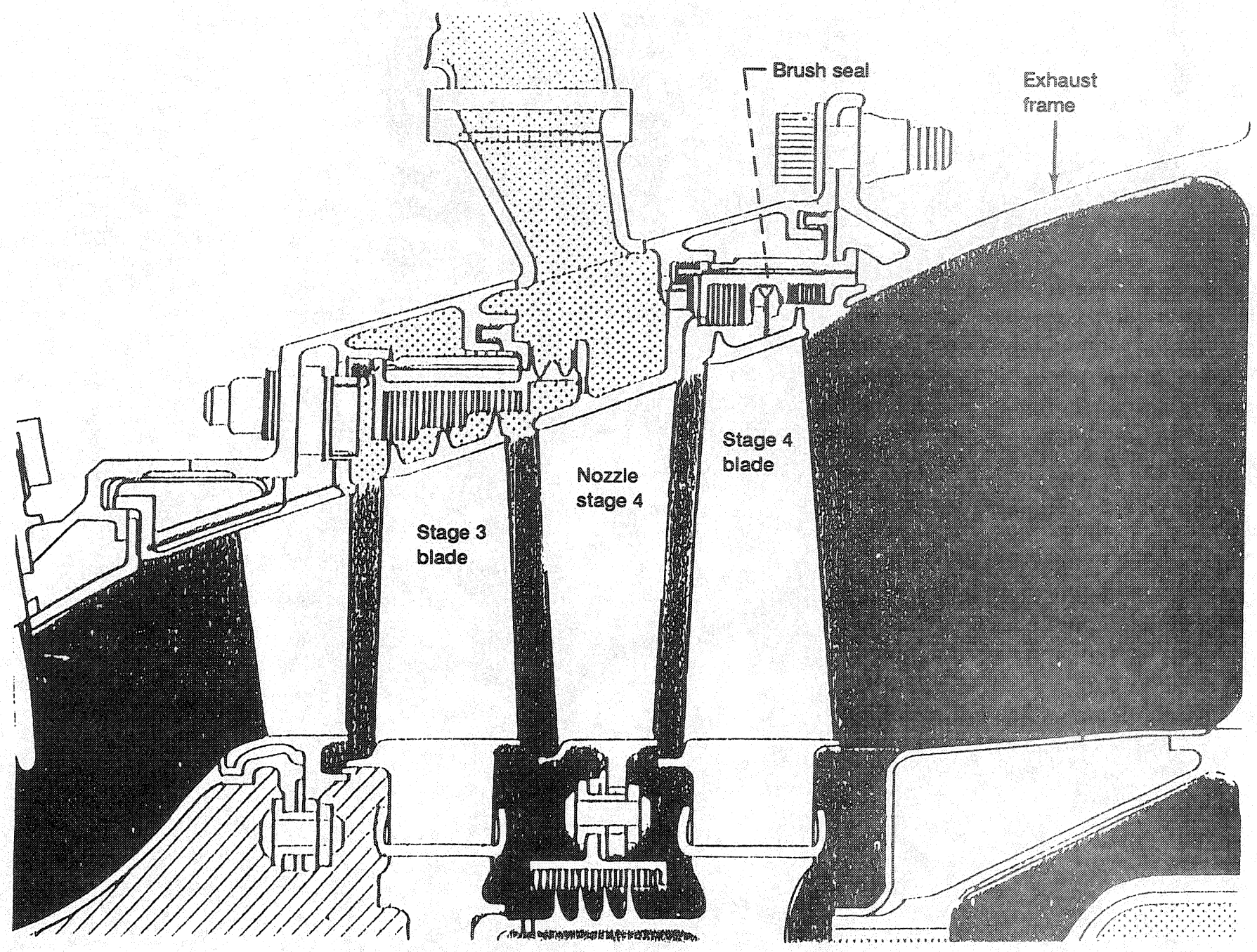

Figure 7. - Schematic of power turbine. 


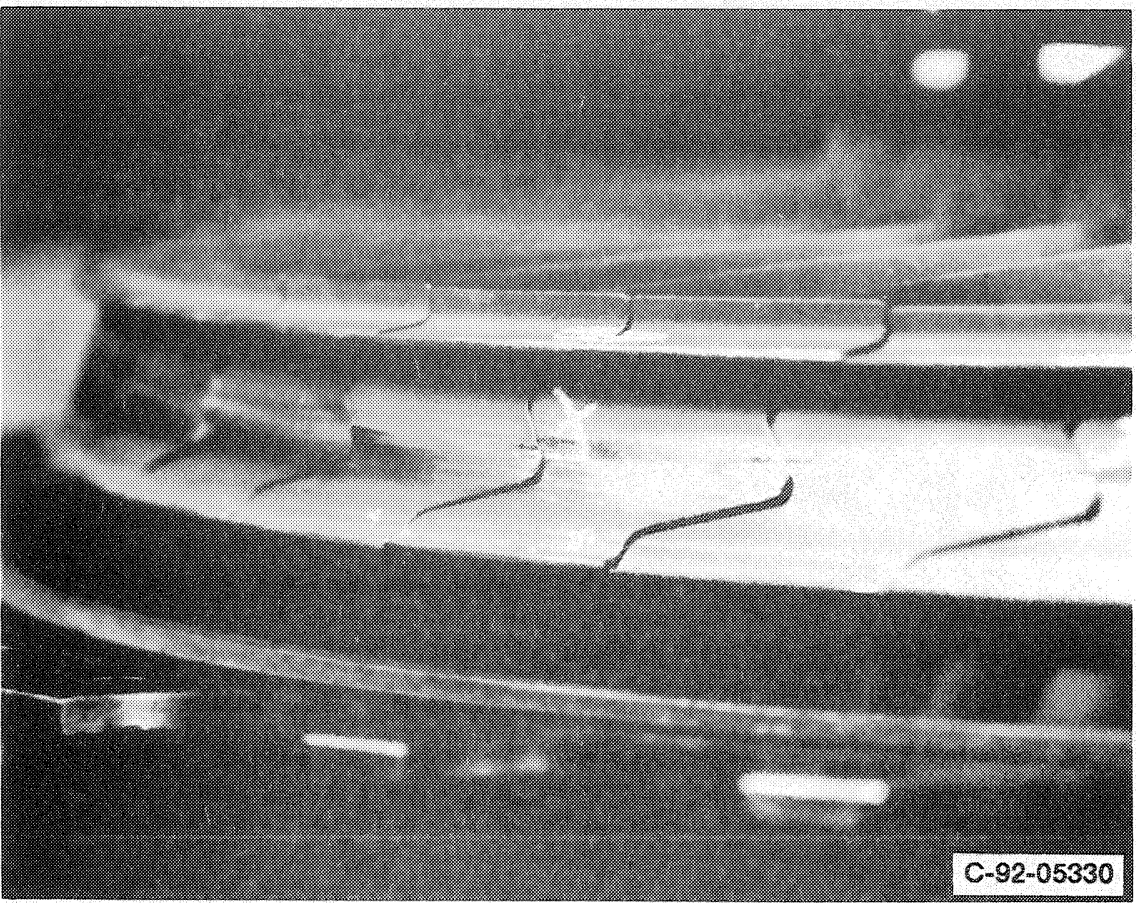

Figure 8.-Fourth-stage turbine after testing, showing polishing of leading edges. 

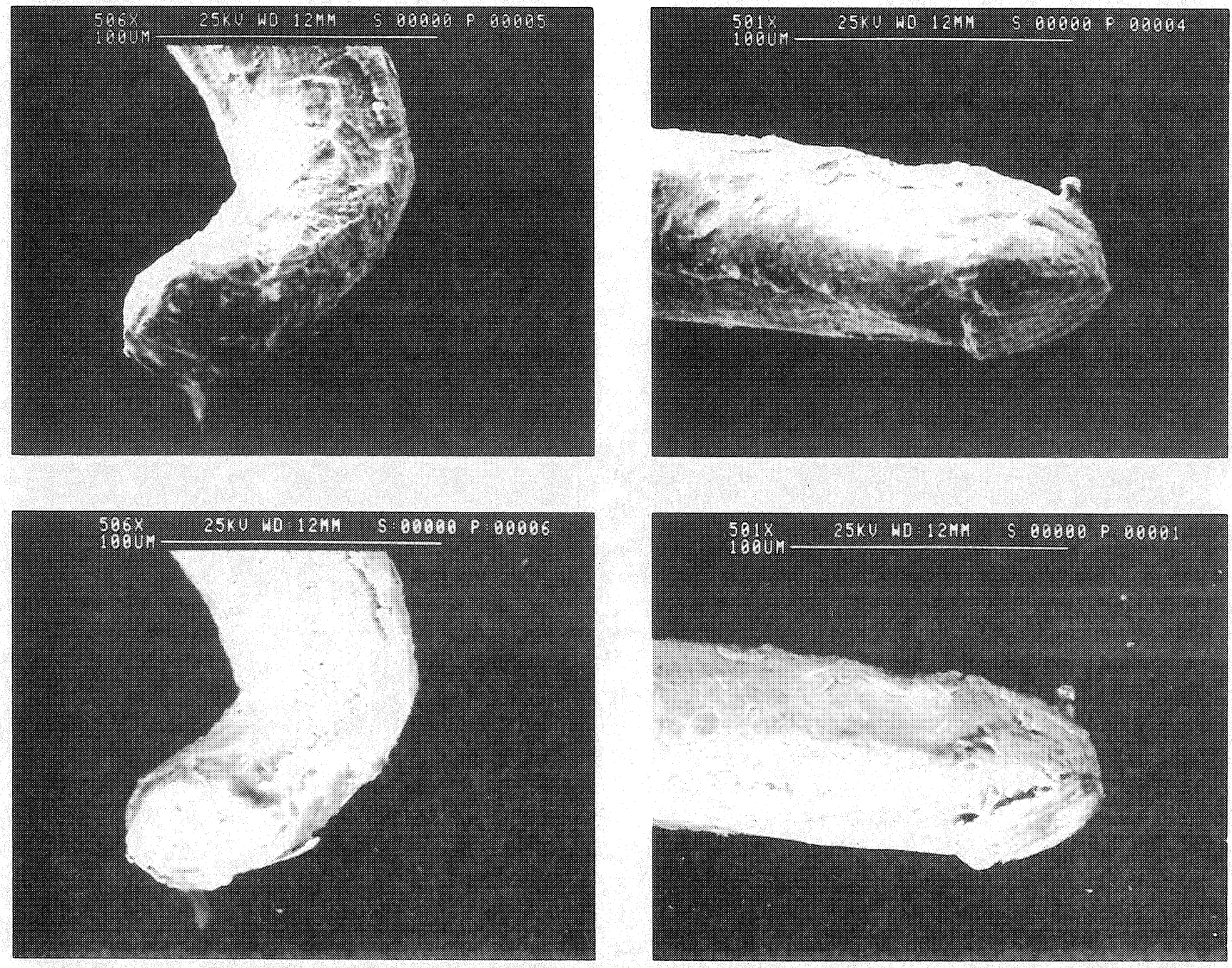

(a) Typical bristle tips.
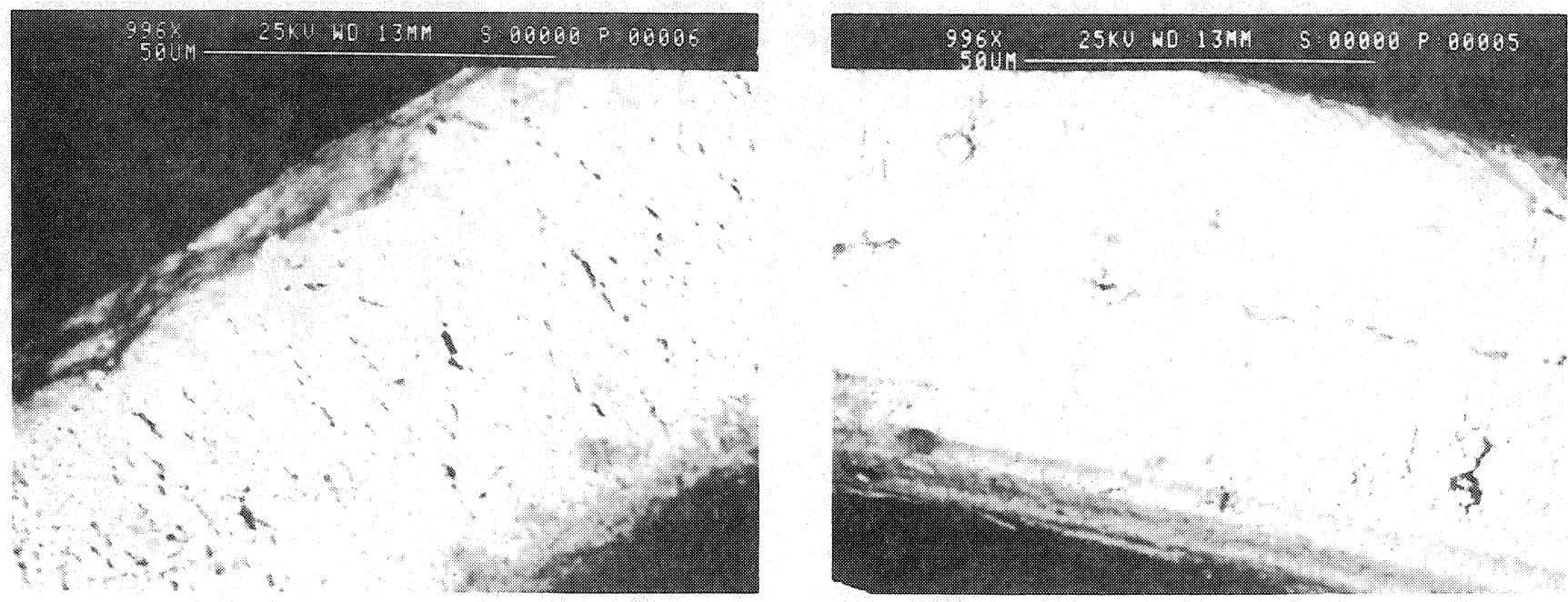

(b) Surface features.

Figure 9.-Typical brush seal debris found in engine exhaust duct. 

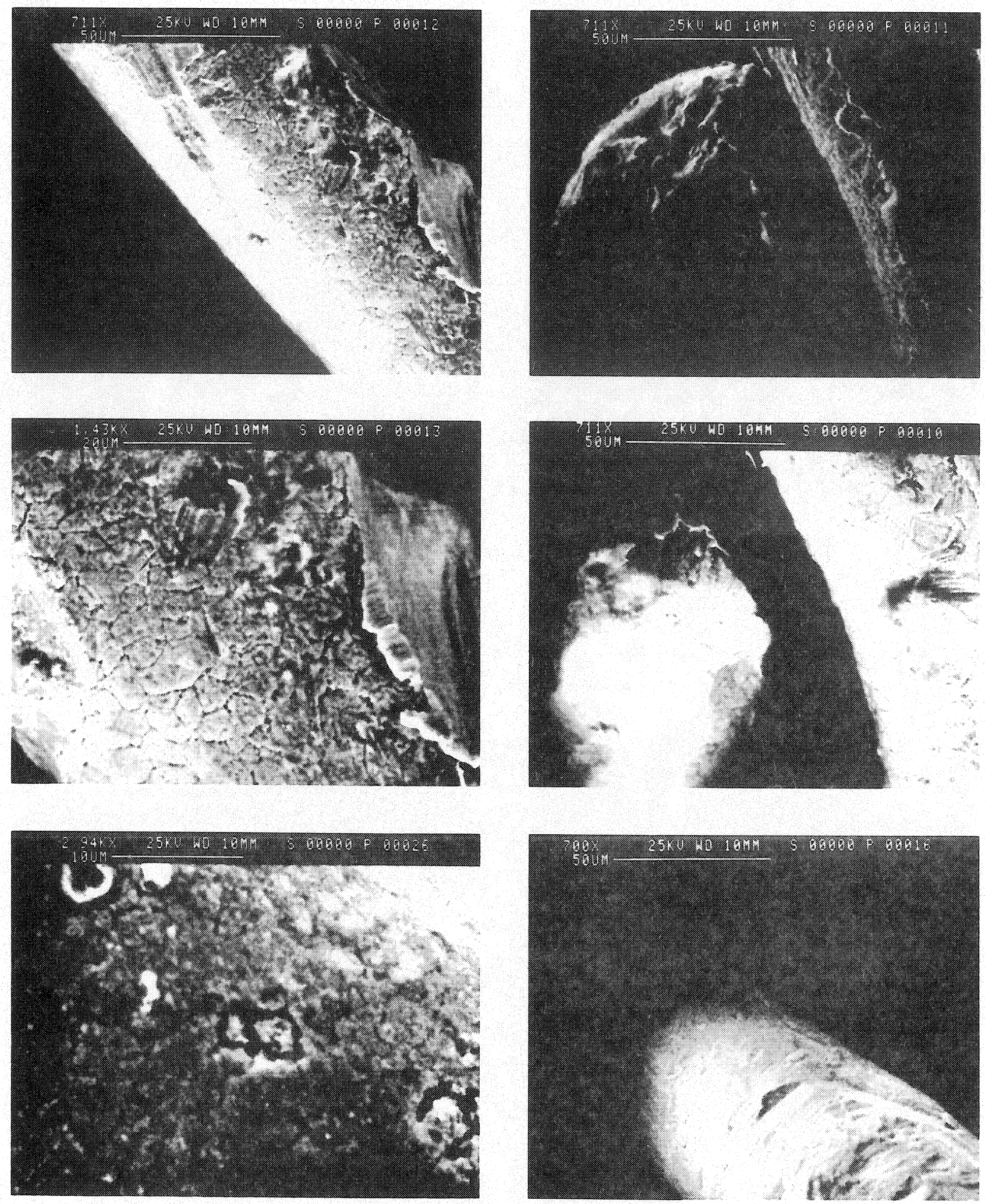

(b) Continued.

Figure 9.-Continued. 

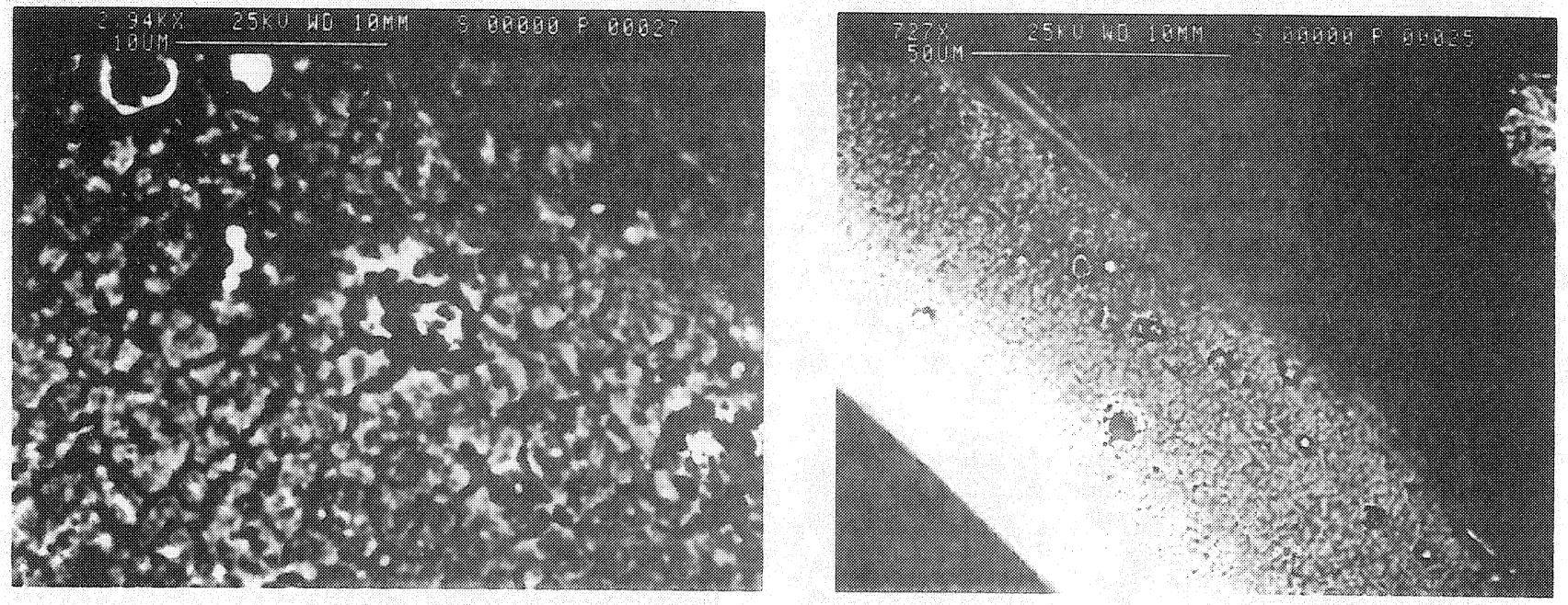

(b) Concluded.

Figure 9.-.-Concluded.

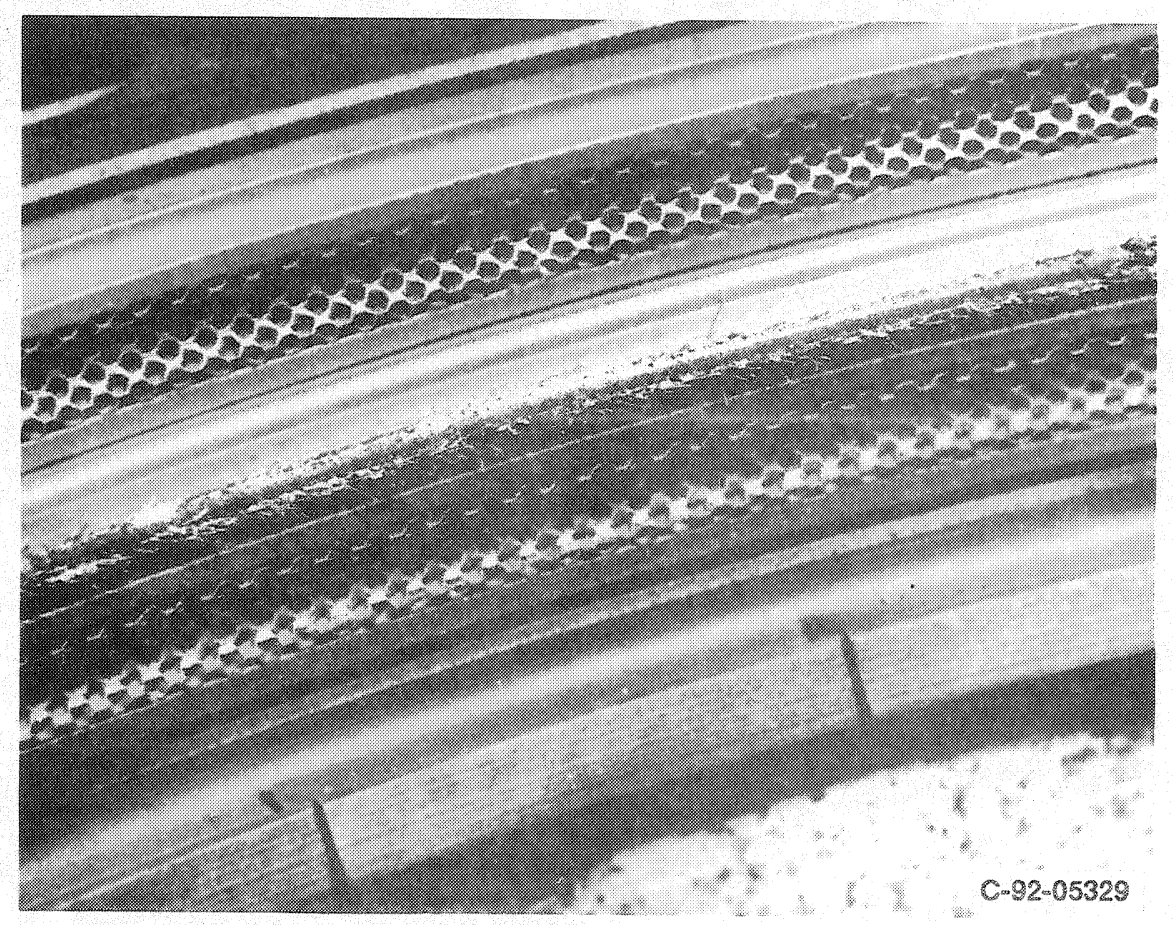

Figure 10.-Post-test view of brush seal showing bristle spreading and core of rubbed bristles. 


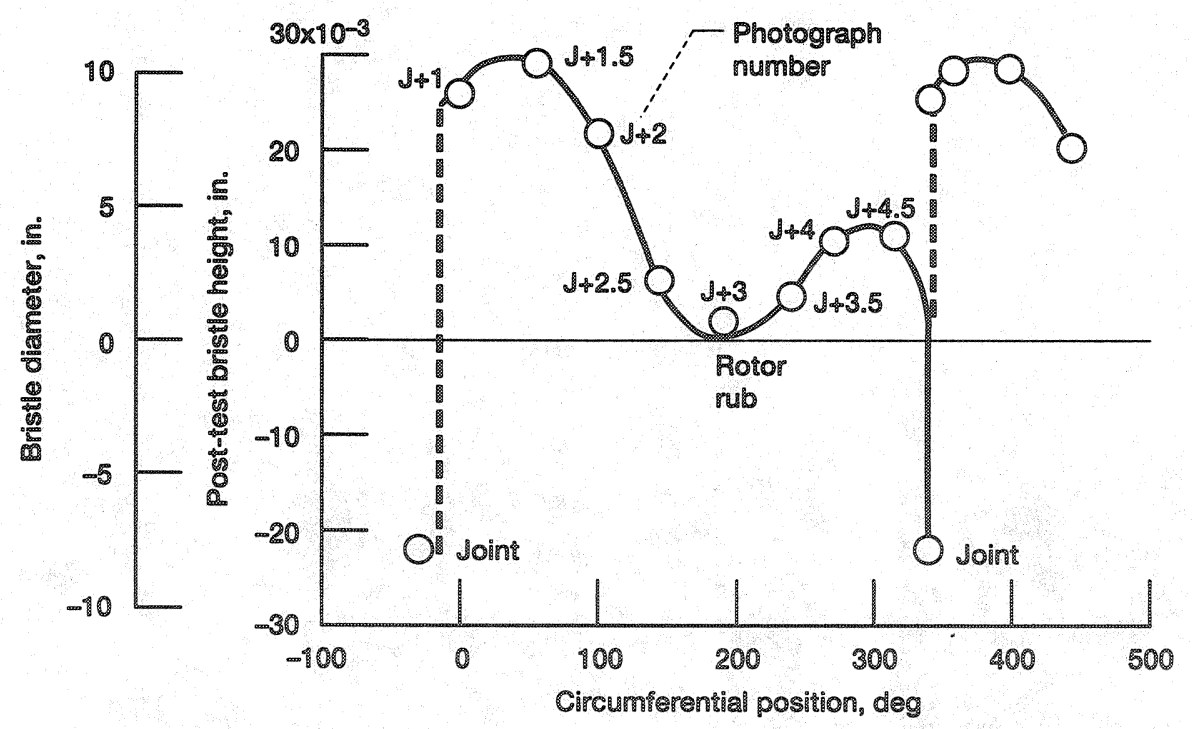

(a) Bristle height versus circumferential position.

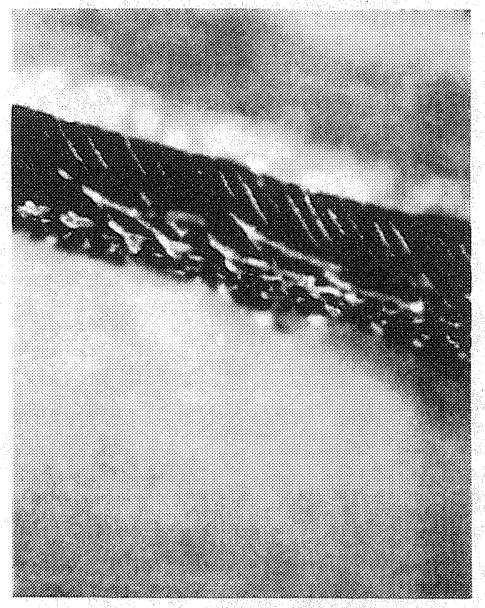

Joint.

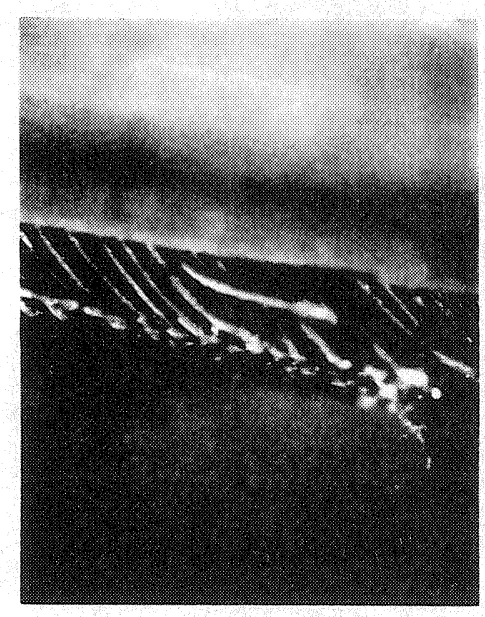

$J+2$

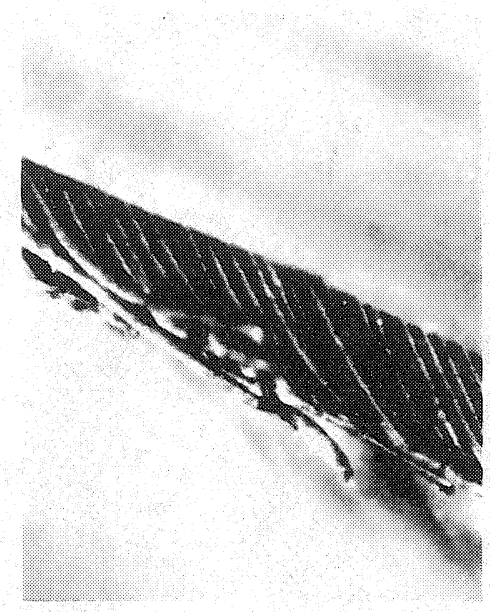

$J+1$

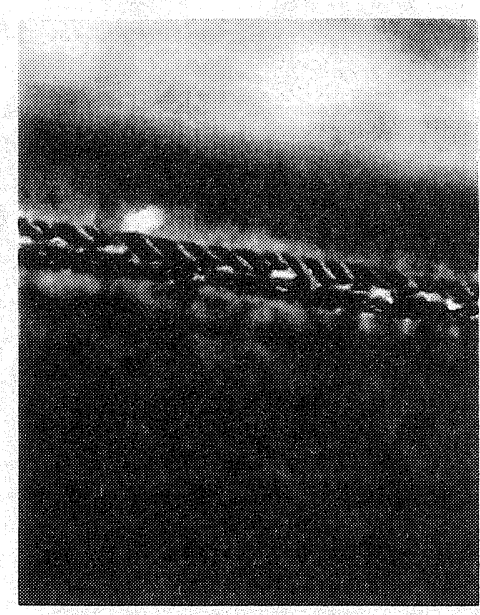

$J+2.5$.

(b) Bristles at backing washer.

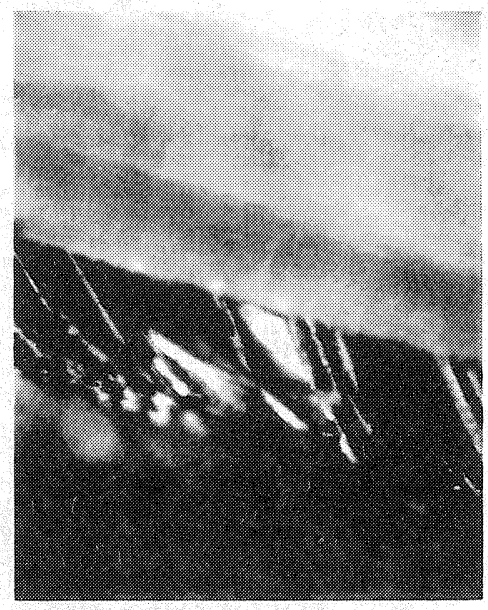

$J+1.5$

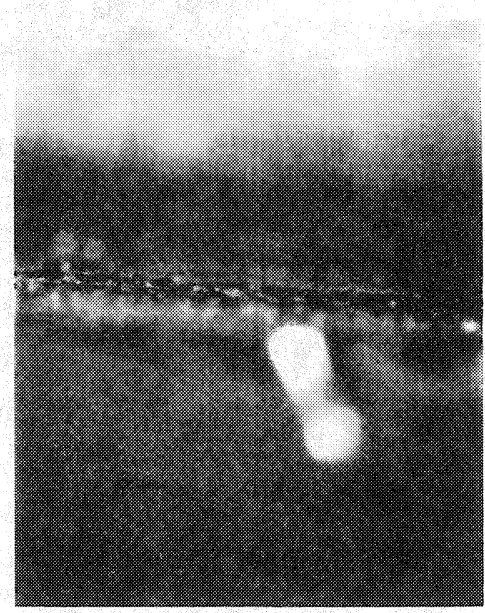

$d+3$

Figure 11.-Post-test bristle stub height and backing washer rub. Bristle diameter, 0.0028 in. 


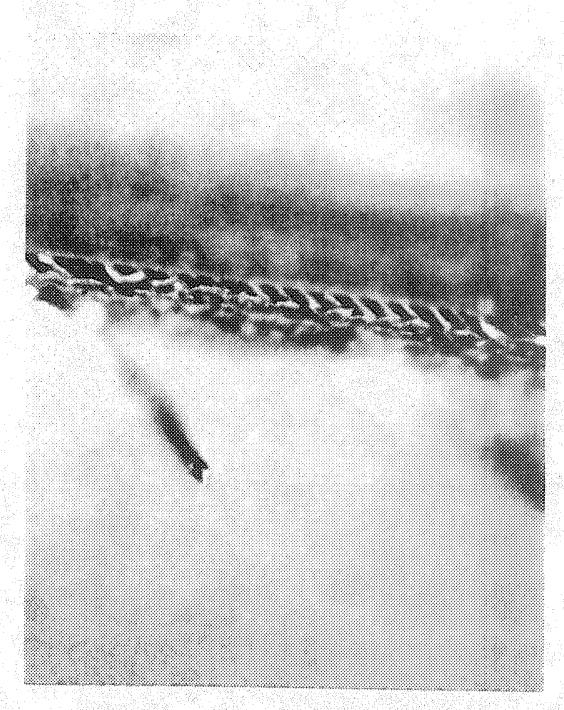

$\jmath+3.5$
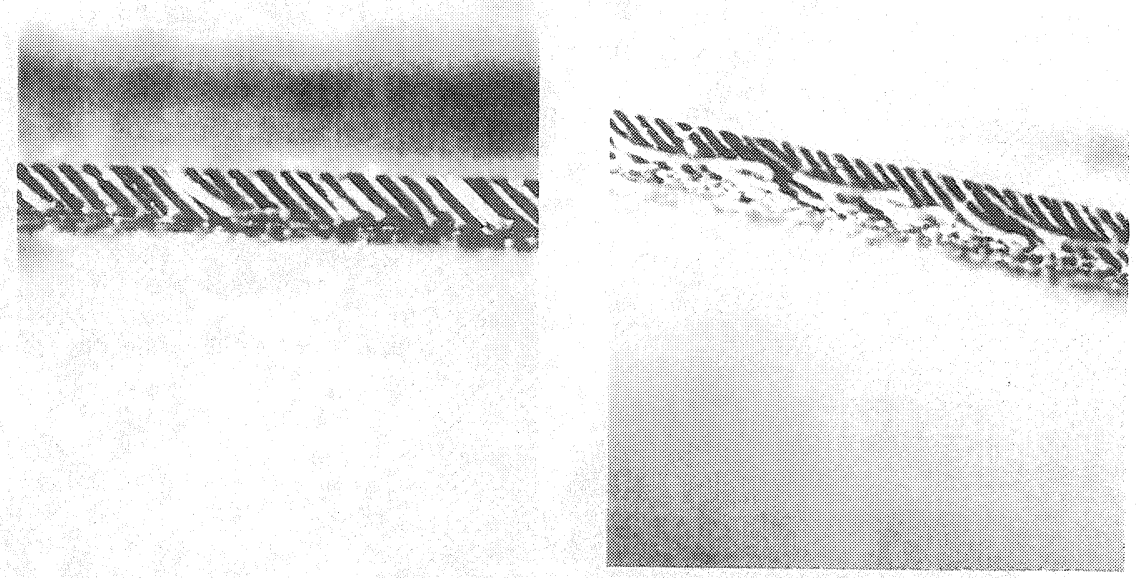

$J+4$

$$
J+4.5 \text {. }
$$

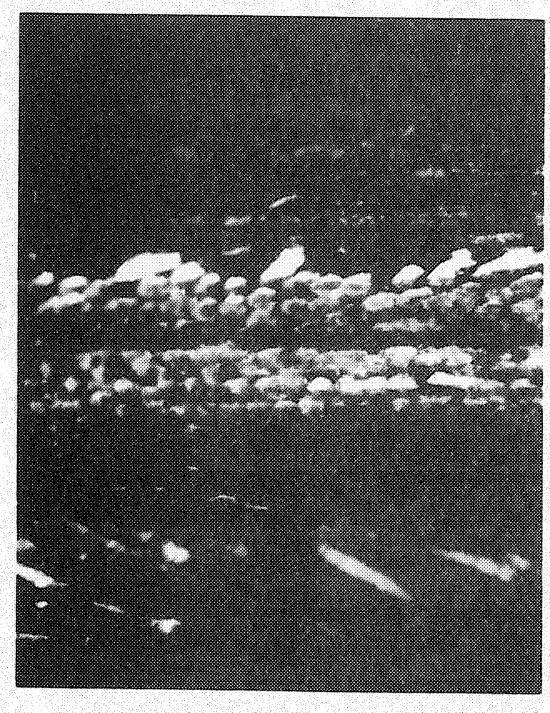

$J+3$ (rotated view) $40 x$

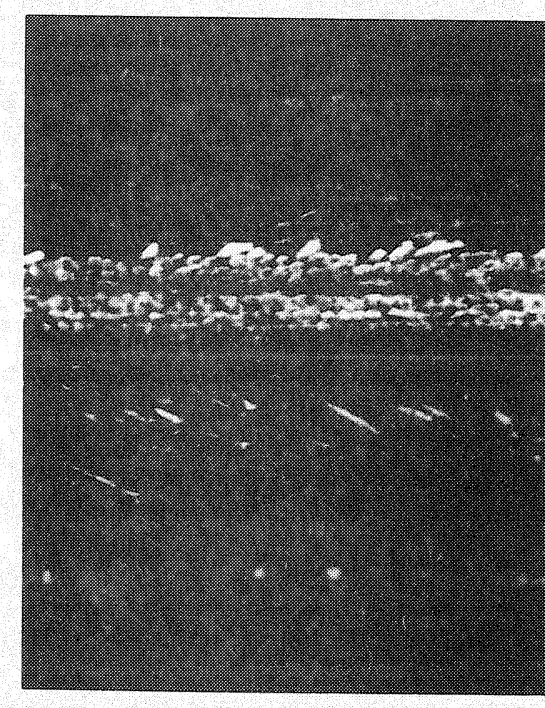

$J+3$ (rotated view) $23 x$

(b) Concluded.

Figure 11.-Continued. 

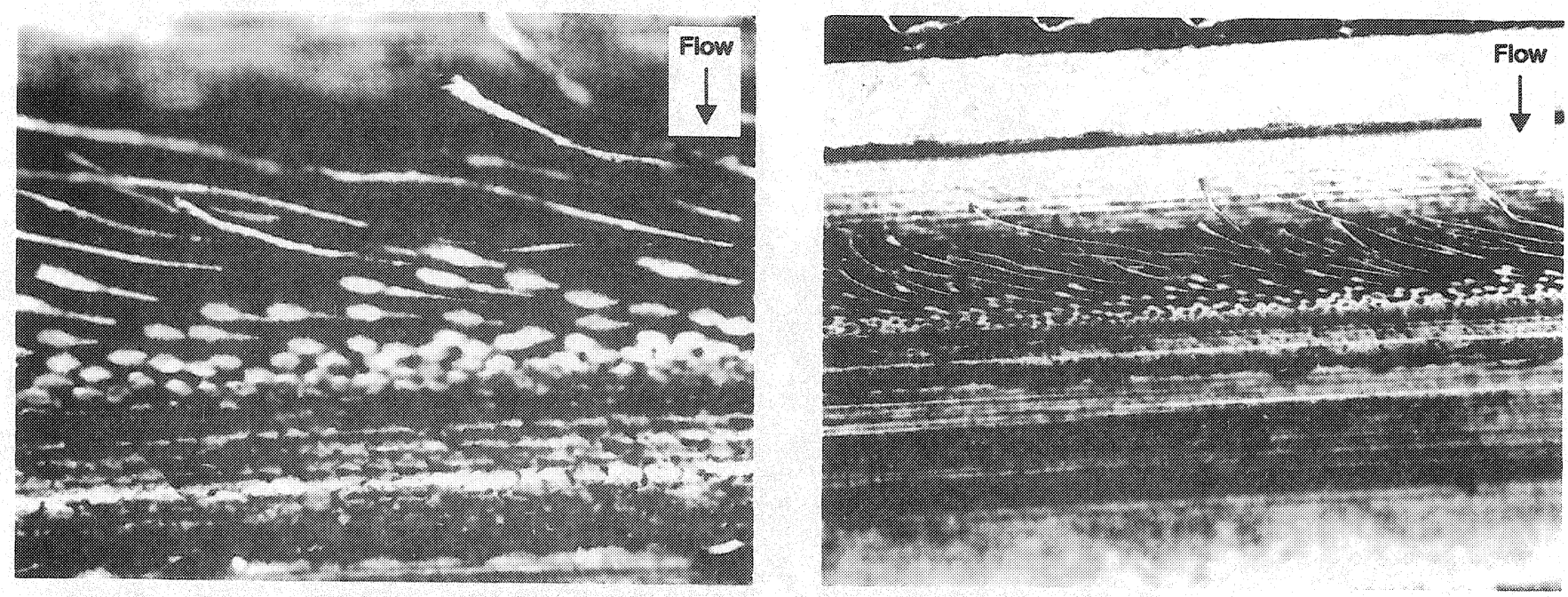

(c) Wear track and fence rub.
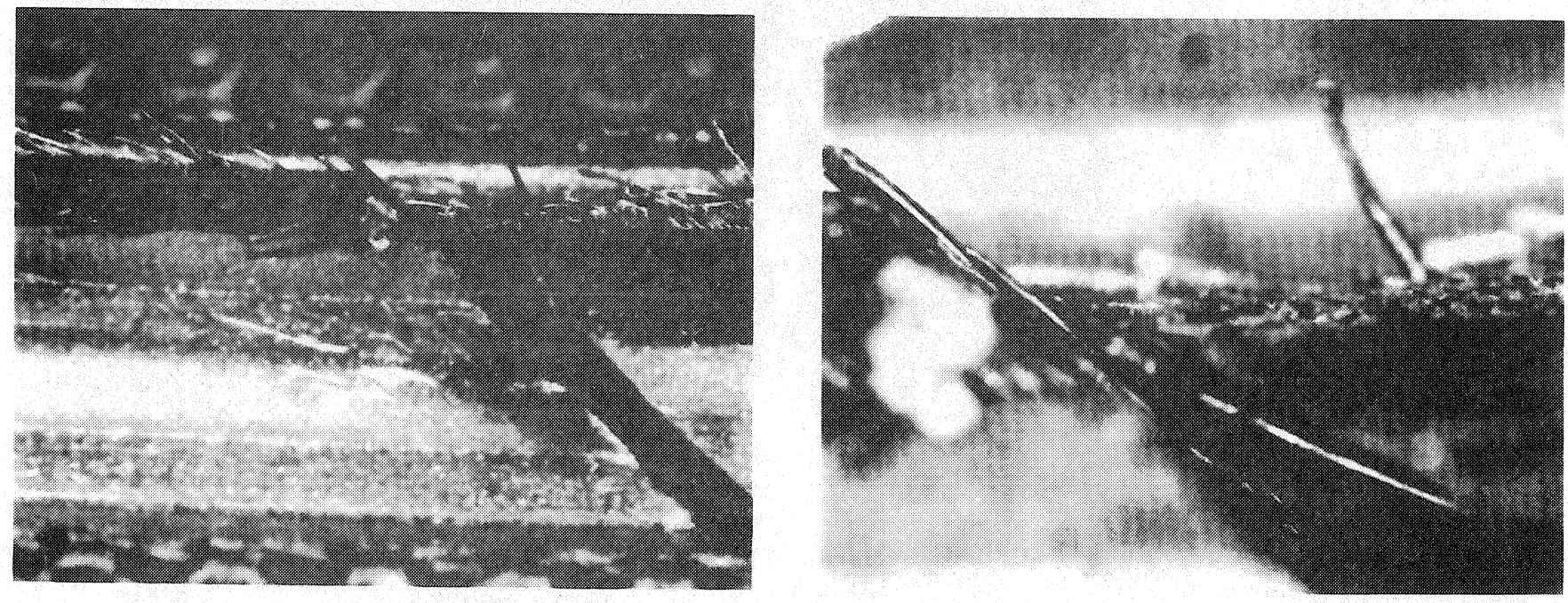

(d) Joint wear track.

Figure 11.-Concluded. 


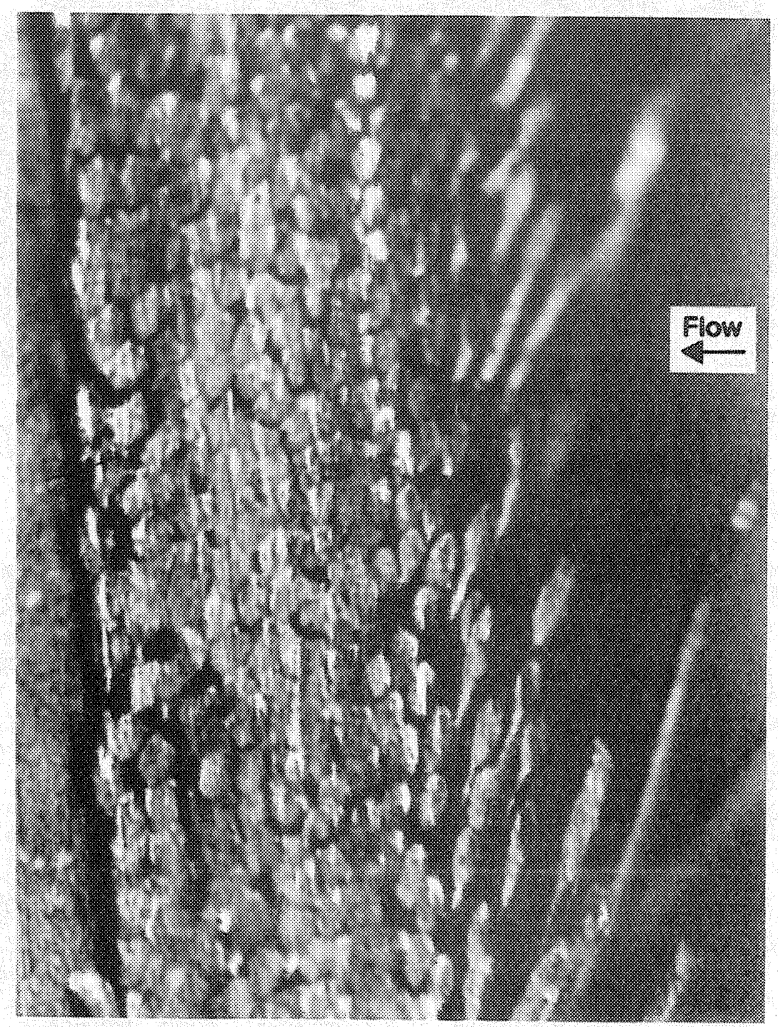

Figure 12.-Details of brush seal wear pattem. 

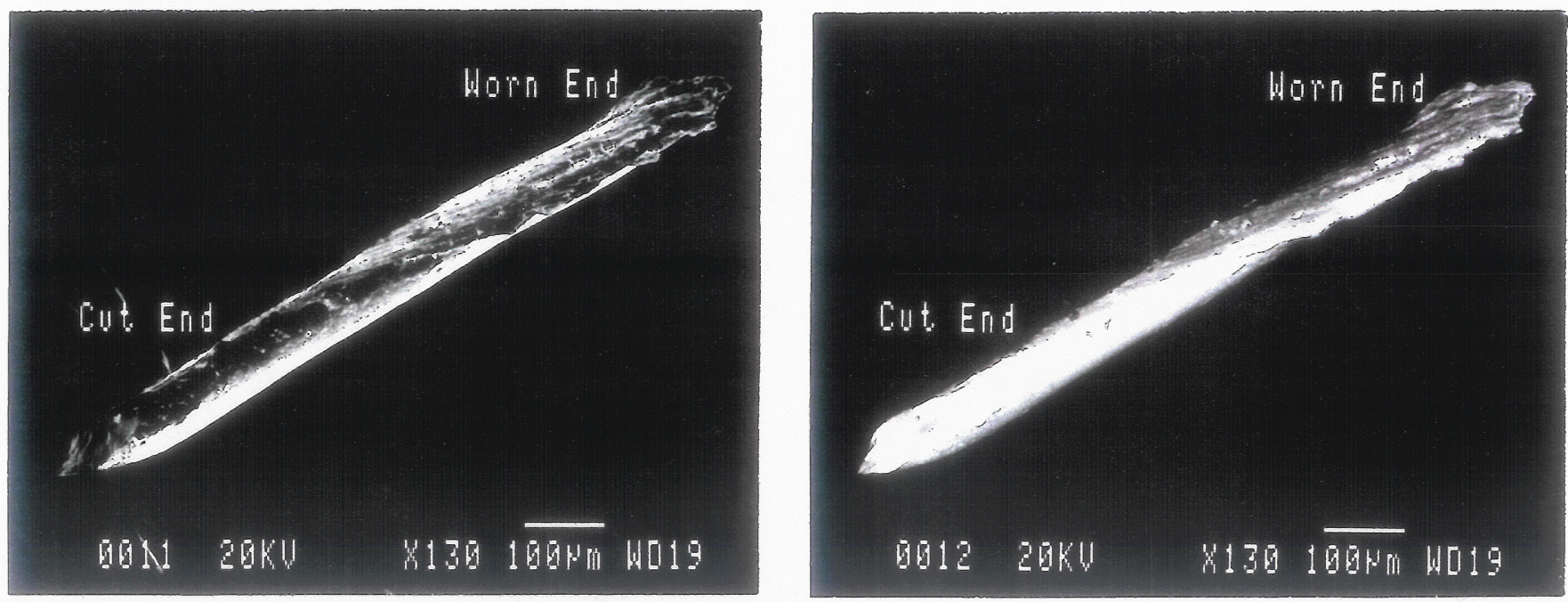

(a) Bristle 1 spread away from wear track.
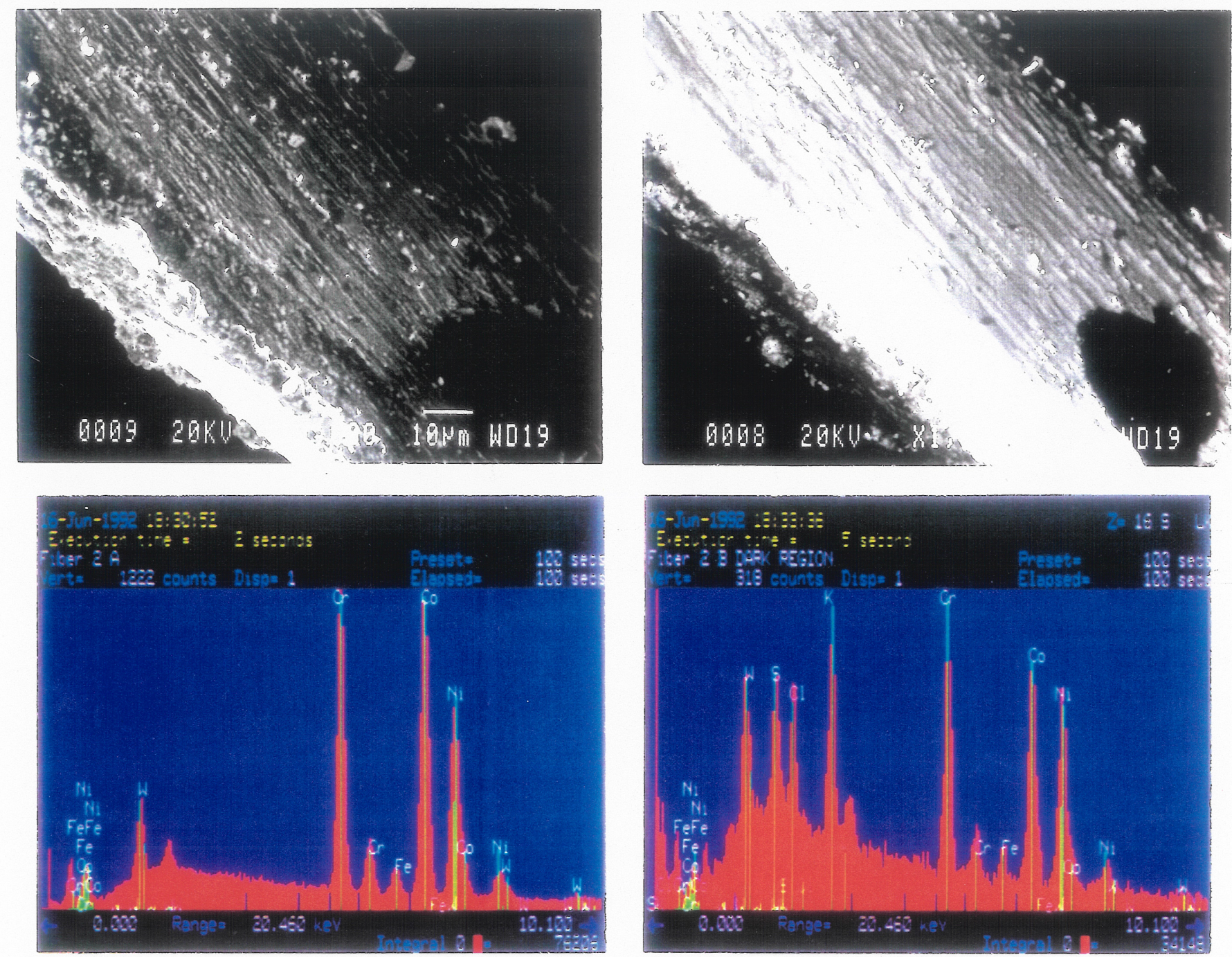

(b) Analysis of bristle 1.

Figure 13.-Post-test metallographic results for single bristle. 

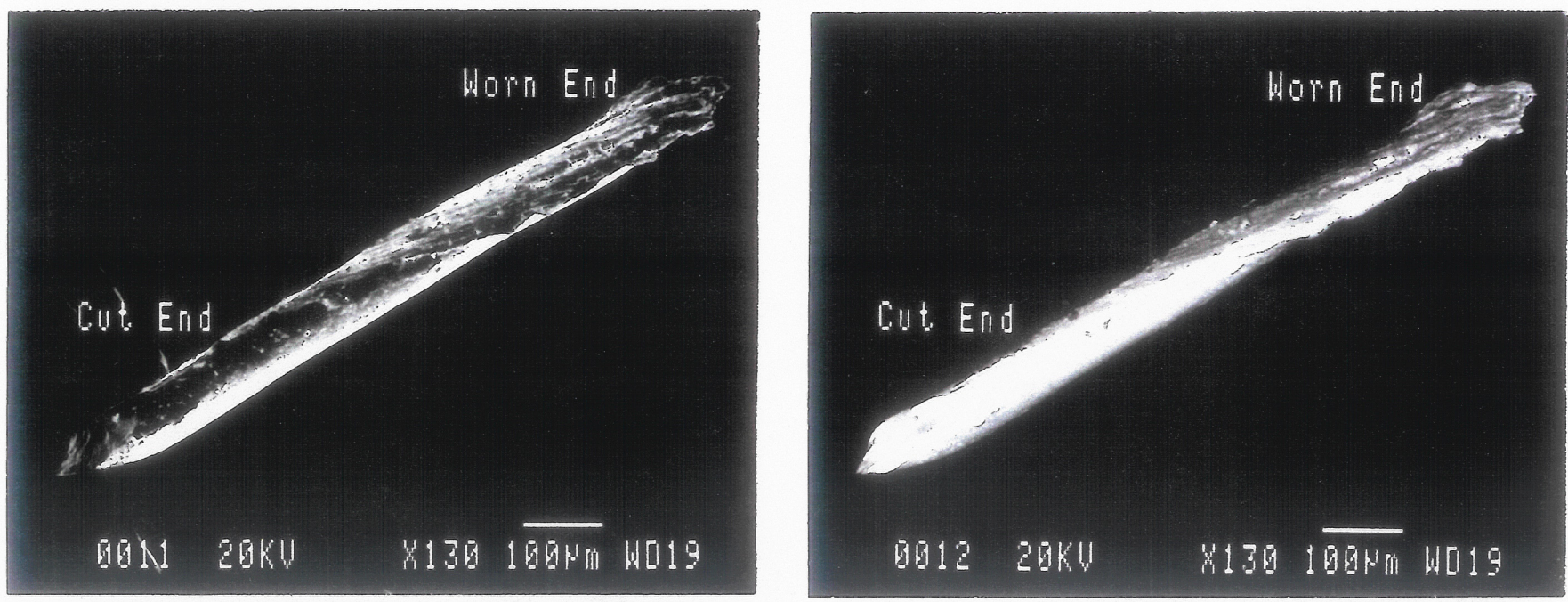

(a) Bristle 1 spread away from wear track.
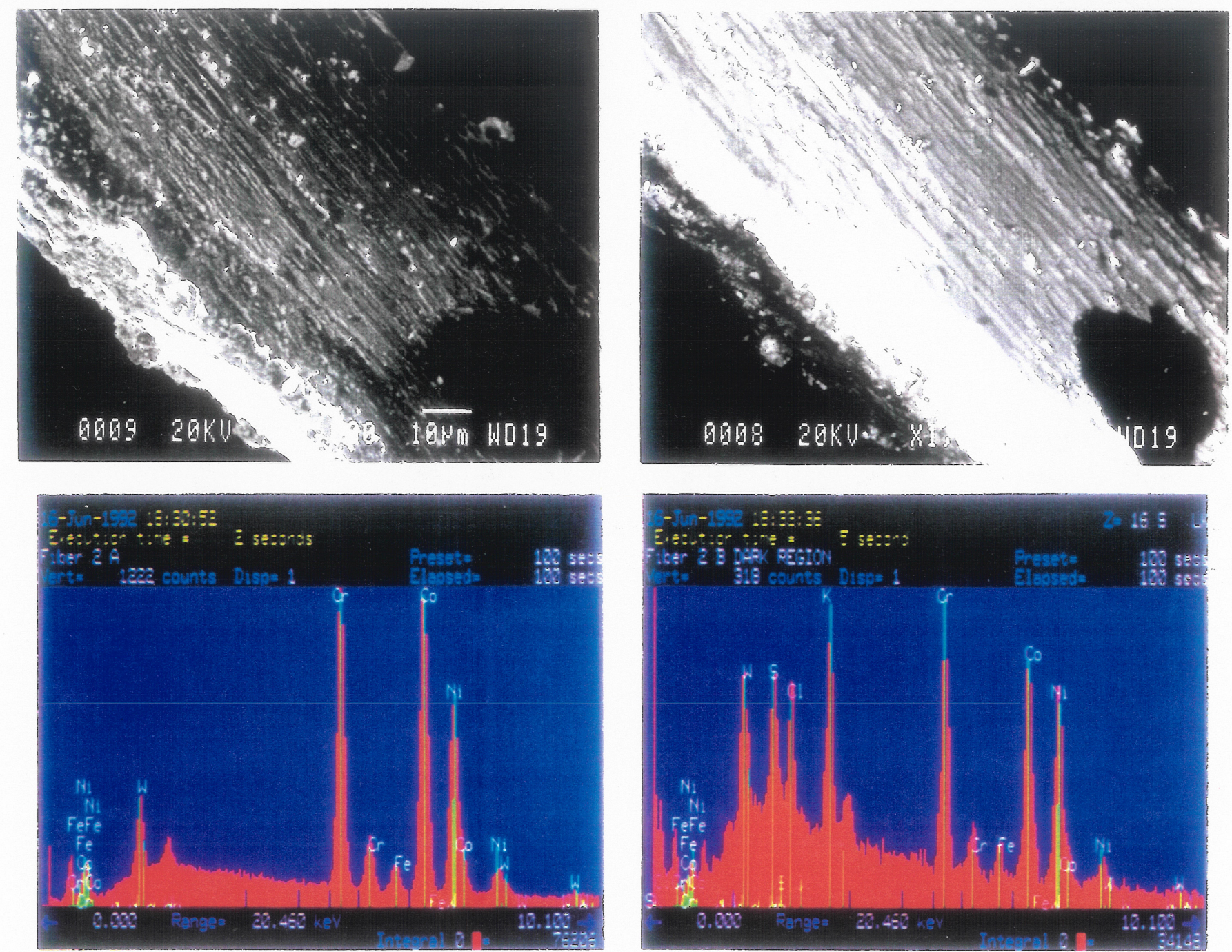

(b) Analysis of bristle 1.

Figure 13.-Post-test metallographic results for single bristle. 

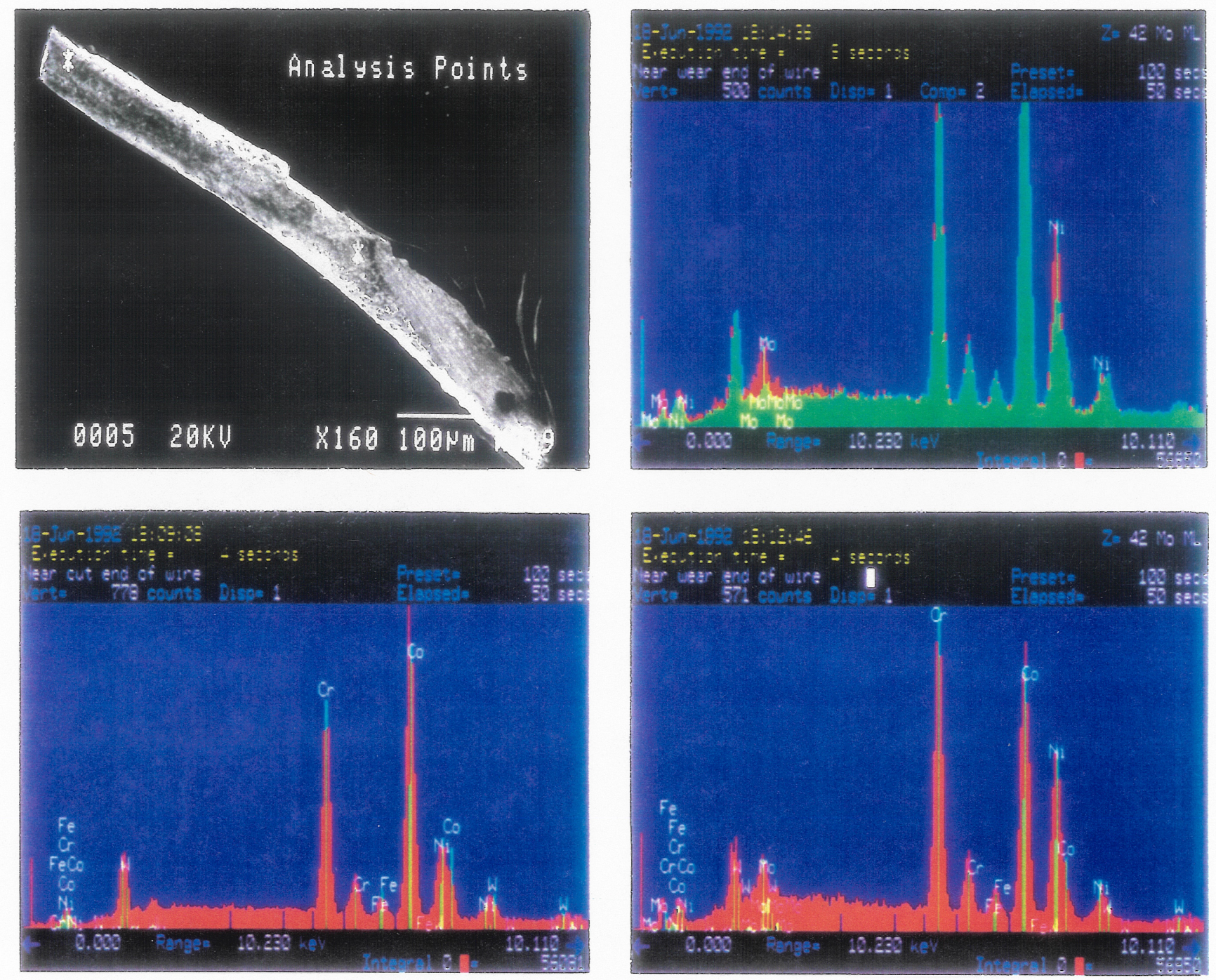

(c) Bristle 1 at increased resolution.

Figure 13.-Concluded. 

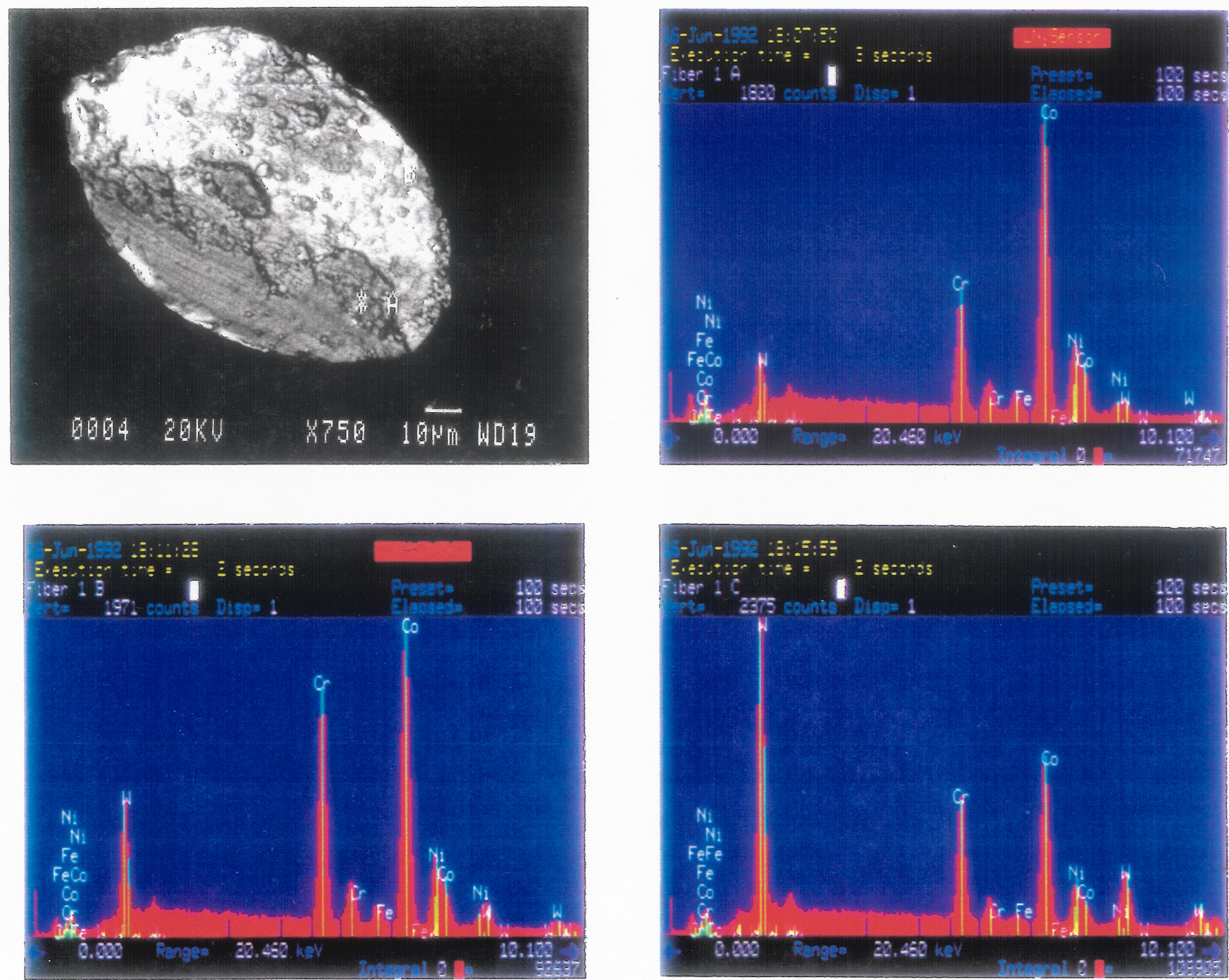

Figure 14.-Post-test metallographic results for bristle tip from wear track. 


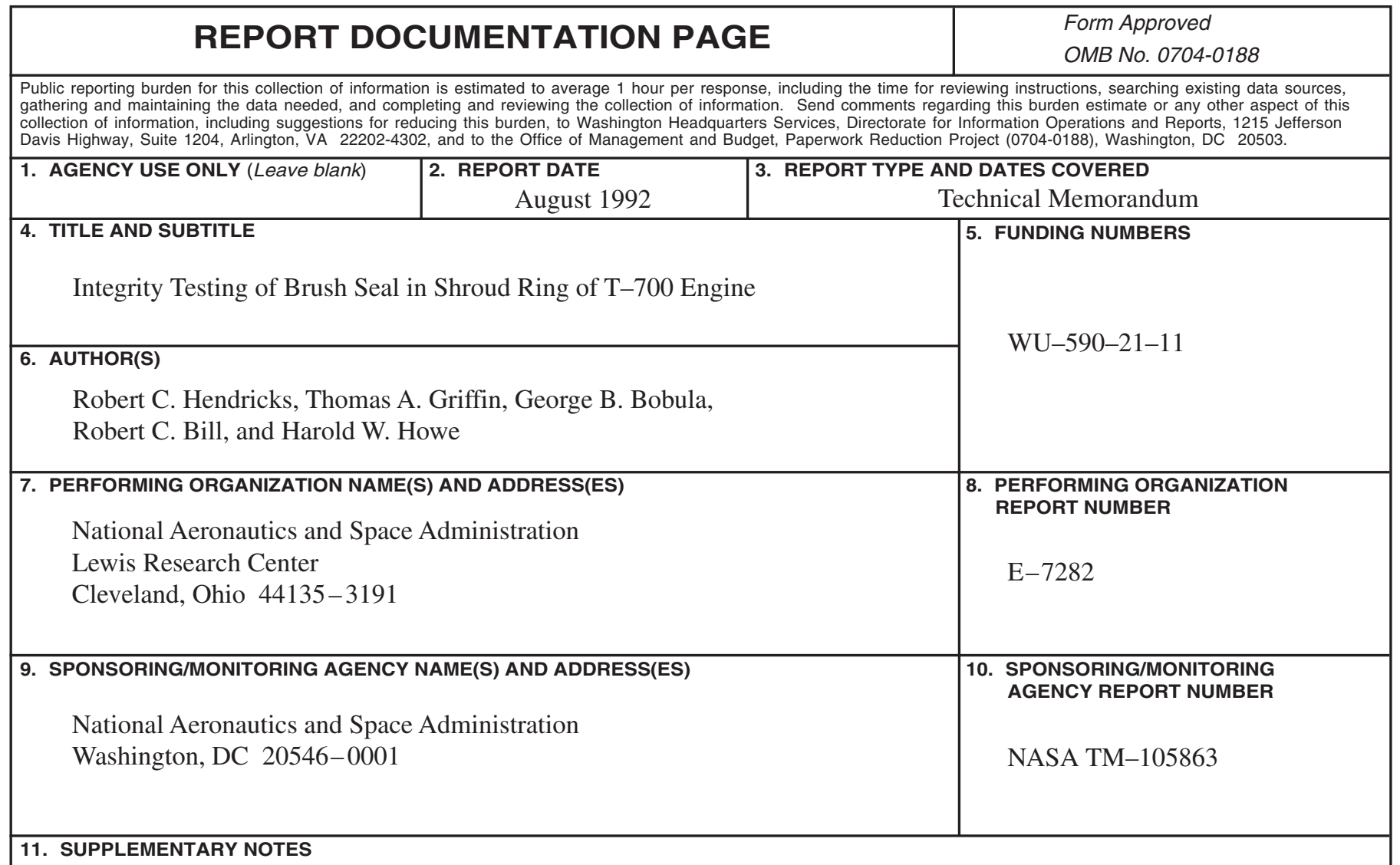

Prepared for the Seals Workshop sponsored by the NASA Lewis Research Center, Cleveland, Ohio, August 5-6, 1992. Robert C. Hendricks, Thomas A. Griffin, George A. Bobula, and Robert C. Bill, Lewis Research Center, Cleveland, Ohio; Harold W. Howe, Technetics Corp., Deland, Florida. Responsible person, Robert C. Hendricks, 216-433-7507.

\begin{tabular}{|l|l|}
\hline 12a. DISTRIBUTION/AVAILABILITY STATEMENT & 12b. DISTRIBUTION CODE
\end{tabular}

Unclassified - Unlimited

Subject Category: 37

Available electronically at http://gltrs.grc.nasa.gov

This publication is available from the NASA Center for AeroSpace Information, 301-621-0390.

13. ABSTRACT (Maximum 200 words)

A split-ring brush seal was fabricated, installed between two labyrinth-honeycomb shroud seals, and tested in the fourth-stage turbine of a T-700 engine. The annealed Haynes 25 bristles rubbed directly against the nonconditioned, irregular René 80 turbine blade shroud surface. A total of $30 \mathrm{hr}$ of cyclic and steady-state data were taken with surface speeds to $335 \mathrm{~m} / \mathrm{s}(1100 \mathrm{ft} / \mathrm{s})$ and shroud temperatures to $620^{\circ} \mathrm{C}\left(1150{ }^{\circ} \mathrm{F}\right)$. Wear appeared to be rapid initially, with an orange flash of hot brush fragments during the first engine startup, to minimal after $10 \mathrm{hr}$ of operation. The brush survived the testing but experienced some bristle pullouts and severe bristle wear; some turbine interface wear and possible material transfer was noted. Future design concerns center on tribological behavior at the interface with or without lubricants.

\begin{tabular}{|c|c|c|c|}
\hline \multicolumn{3}{|l|}{ 14. SUBJECT TERMS } & 15. NUMBER OF PAGES \\
\hline \multicolumn{3}{|l|}{ Seal; Shroud; Brush } & \begin{tabular}{|c|}
28 \\
16. PRICE CODE
\end{tabular} \\
\hline & & & A03 \\
\hline Unclassified & Unclassified & Unclassified & \\
\hline
\end{tabular}

